\title{
Characterizing photosymbiosis in modern planktonic foraminifera
}

\author{
Haruka Takagi ${ }^{1,2}$, Katsunori Kimoto ${ }^{3}$, Tetsuichi Fujiki ${ }^{3}$, Hiroaki Saito ${ }^{1}$, Christiane Schmidt ${ }^{4}$, Michal Kucera ${ }^{4}$, and \\ Kazuyoshi Moriya ${ }^{5}$ \\ ${ }^{1}$ Atmosphere and Ocean Research Institute, The University of Tokyo, Chiba, Japan \\ ${ }^{2}$ Graduate School of Creative Science and Engineering, Waseda University, Tokyo, Japan \\ ${ }^{3}$ Japan Agency for Earth-Marine Science and Technology, Kanagawa, Japan \\ ${ }^{4}$ MARUM - Center for Marine Environmental Sciences and Faculty of Geosciences, University of Bremen, Bremen, \\ Germany \\ ${ }^{5}$ Department of Earth Sciences, School of Education, Waseda University, Tokyo, Japan
}

Correspondence: Haruka Takagi (htakagi@aori.u-tokyo.ac.jp, harurah-t@ fuji.waseda.jp)

Received: 18 April 2019 - Discussion started: 26 April 2019

Revised: 7 August 2019 - Accepted: 8 August 2019 - Published: 5 September 2019

\begin{abstract}
Photosymbiosis has played a key role in the diversification of foraminifera and their carbonate production throughout geologic history. However, identification of photosymbiosis in extinct taxa remains challenging, and even among the extant species the occurrence and functional relevance of photosymbiosis remain poorly constrained. Here, we investigate photosymbiosis in living planktonic foraminifera by measuring active chlorophyll fluorescence with fast repetition rate fluorometry. This method provides unequivocal evidence for the presence of photosynthetic capacity in individual foraminifera, and it allows us to characterize multiple features of symbiont photosynthesis including chlorophyll $a$ ( $\mathrm{Chl} a$ ) content, potential photosynthetic activity $\left(F_{\mathrm{v}} / F_{\mathrm{m}}\right)$, and light-absorption efficiency $\left(\sigma_{\mathrm{PSII}}\right)$. To obtain robust evidence for the occurrence and importance of photosymbiosis in modern planktonic foraminifera, we conducted measurements on 1266 individuals from 30 species of the families Globigerinidae, Hastigerinidae, Globorotaliidae, and Candeinidae. Among the studied species, 19 were recognized as symbiotic and 11 as non-symbiotic. Of these, six species were newly confirmed as symbiotic and five as non-symbiotic. Photosymbiotic species have been identified in all families except the Hastigerinidae. A significant positive correlation between test size and $\mathrm{Chl} a$ content, found in 16 species, is interpreted as symbiont abundance scaled to the growth of the host and is consistent with persistent possession of symbionts through the lifetime of the foraminifera. The remaining three symbiont-bearing species did not show such a relationship, and their $F_{\mathrm{v}} / F_{\mathrm{m}}$ values were compara-
\end{abstract}

tively low, indicating that their symbionts do not grow once acquired from the environment. The objectively quantified photosymbiotic characteristics have been used to design a metric of photosymbiosis, which allows the studied species to be classified along a gradient of photosynthetic activity, providing a framework for future ecological and physiological investigations of planktonic foraminifera.

\section{Introduction}

Planktonic foraminifera are unicellular heterotrophic marine zooplankton with calcareous tests. Since they are geographically widespread and abundant, and can be preserved in seafloor sediments as microfossils, foraminifera are one of the most important archives of past surface ocean conditions. They have been used to investigate pelagic marine biodiversity dynamics from middle Mesozoic to the present (Bolli et al., 1985; Norris, 1991; Boudagher-Fadel et al., 1997; Hull, 2017; Yasuhara et al., 2017). Recent studies of macroevolutionary dynamics of planktonic foraminifera emphasize the importance of species ecology including photosymbiosis (endosymbiosis with autotrophic algae) as a key player determining temporal and spatial patterns of species diversity (Ezard et al., 2011; Fenton et al., 2016). However, identifying photosymbiosis in extinct species is difficult and requires indirect evidence such as size-dependent stable isotopic trends (e.g., Pearson et al., 1993; Norris, 1996). These indirect methods must be benchmarked by observations from 
living foraminifera, in which the presence of symbionts can be determined directly. Knowledge on the prevalence, diversity, and phylogenetic position of photosymbiosis is also required to elucidate ecological and evolutionary strategies of the involved clades and to characterize key features of foraminiferal test geochemistry such as $\delta^{13} \mathrm{C}$ and $\delta^{11} \mathrm{~B}$ (e.g., Spero and DeNiro, 1987; Hönisch et al., 2003; Henehan et al., 2013; Ezard et al., 2015).

Photosymbiosis in modern planktonic foraminifera has been empirically identified based on microscopic observations of intracellular algae (Lee et al., 1965; Anderson and Bé, 1976; Gastrich, 1987) and molecular confirmation of algal DNA extracted from a single foraminifera cell (Gast and Caron, 1996; Gast et al., 2000; Shaked and de Vargas, 2006; Bird et al., 2017, 2018). As a result, among the $\sim 50$ species of modern planktonic foraminifera, 12 have so far been reported to be photosymbiotic with eukaryotic algae (Orbulina universa, Globigerinoides sacculifer, Globigerinoides conglobatus, Globigerinoides ruber, Globigerinella siphonifera, Turborotalita humilis, Neogloboquadrina dutertrei, Pulleniatina obliquiloculata, Globorotalia inflata, Globorotalia menardii, Candeina nitida, and Globigerinita glutinata), and six have been reported to be symbiont barren (Hastigerina pelagica, Globigerina bulloides, Globorotalia truncatulinoides, Globorotalia hirsuta, Neogloboquadrina incompta, and Neogloboquadrina pachyderma) (Table 1). The remaining $\sim 30$ species have not been systematically examined for the presence of symbionts. In a strict sense, some previous studies on photosymbiotic association could not differentiate whether the intracellular algae identified were symbionts or just captured prey to be digested. Although observations of features such as mitosis (cell division) of the intracellular algal cells provide strong evidence that these were alive within the foraminifera, the presence of intracellular algae alone does not guarantee that they act as photosymbionts. Many species ingest phytoplankton prey (Anderson et al., 1979), which makes it difficult to differentiate symbionts or prey, especially by DNA analysis. Since many species of planktonic foraminifera do not survive well in culture, it is hard to conduct behavioral or physiological experiments to confirm their symbiosis. These limitations have hindered the progress of studies of photosymbiosis targeting various species of planktonic foraminifera.

One solution to identify functional photosymbiosis is to detect a physiological signature of photosynthesis within the cell. This has been done by measurements of oxygen production with microelectrodes (Jørgensen et al., 1985; Rink et al., 1998; Lombard et al., 2009) or a determination of photosynthetic carbon fixation by measurements of the ${ }^{14} \mathrm{C}$ tracer (Spero and Parker, 1985; Gastrich and Bartha, 1988). These studies were limited to established symbiotic species that are easy to culture (e.g., O. universa, G. sacculifer, and G. siphonifera). For the other species, especially non-spinose species (e.g., N. dutertrei, P. obliquiloculata, and G. glutinata), the physiological characteristics of their photosym- biosis have never been described. Therefore, our knowledge of modern photosymbiosis has been exclusively obtained from a small number of spinose symbiotic species. A powerful alternative to directly and unambiguously determine the presence of active photosynthesis in the foraminifera is given by the measurement of fluorescence induced by light capture in the photosystem II of the algal chlorophyll. These methods have been used in benthic symbiontbearing foraminifera (e.g., Uthicke, 2006; Schmidt et al., 2011; Ziegler and Uthicke, 2011) and have been recently successfully adapted for application on single specimens of living planktonic foraminifera (Fujiki et al., 2014; Takagi et al., 2016, 2018). Active chlorophyll fluorometry performs nondestructive and non-invasive measurements of algal physiology based on real-time variable fluorescence profiles (Kolber and Falkowski, 1993), allowing us to quantify chlorophyll $a$ content of a specimen, the health of its symbionts, and their light-level adaptation (Fujiki et al., 2014; Takagi et al., 2018). The measurements can be performed almost immediately after collection, with minimal manipulations, and thus minimizing damage to the foraminifera and circumventing the culturing of stress-induced artifacts. This approach could make a breakthrough in the study of photosymbiosis, not just because of its versatility but because of its potential to provide key quantitative attributes of the photosymbiosis.

Symbiotic relationships in planktonic foraminifera have been previously categorized as being either obligate or facultative (Hemleben et al., 1989). Obligate photosymbiosis is essential for the host and makes it functionally mixotrophic, which is an adaptive strategy to live in oligotrophic and welllit parts of the ocean (Hallock, 1981; Stoecker, 1998; Caron, 2000; Lee, 2006). In facultative symbiosis, the foraminifera are not dependent upon it for survival, and as a result symbiotic algae in facultative symbiosis will be only found in some specimens of the host species. Facultative associations generally do not involve extensive metabolic adaptation of the host and can thus enhance the flexibility of nutritional sources with minimal energetic investment (Stoecker et al., 2009). In planktonic foraminifera, species always found with intact intracellular algae have been regarded as obligate symbiotic species, whereas species sometimes found with or sometimes without them have been termed as facultative symbiotic species (Hemleben et al., 1989). However, most of our knowledge of foraminiferal photosymbiosis is based on indirect evidence, which is insufficient to categorize planktonic foraminiferal photosymbiosis as either obligate or facultative. Rather, the persistence and functional relevance of the symbiotic relationship through foraminiferal lifetime should be determined anew, using direct measurements, which would allow us to correctly understand the function of each specific photosymbiotic relationship.

Here, we present the results of active chlorophyll fluorometry of 30 species of modern planktonic foraminifera obtained from 1266 individuals. The main purpose of this study is (1) to provide information on the biomass of symbionts (in- 


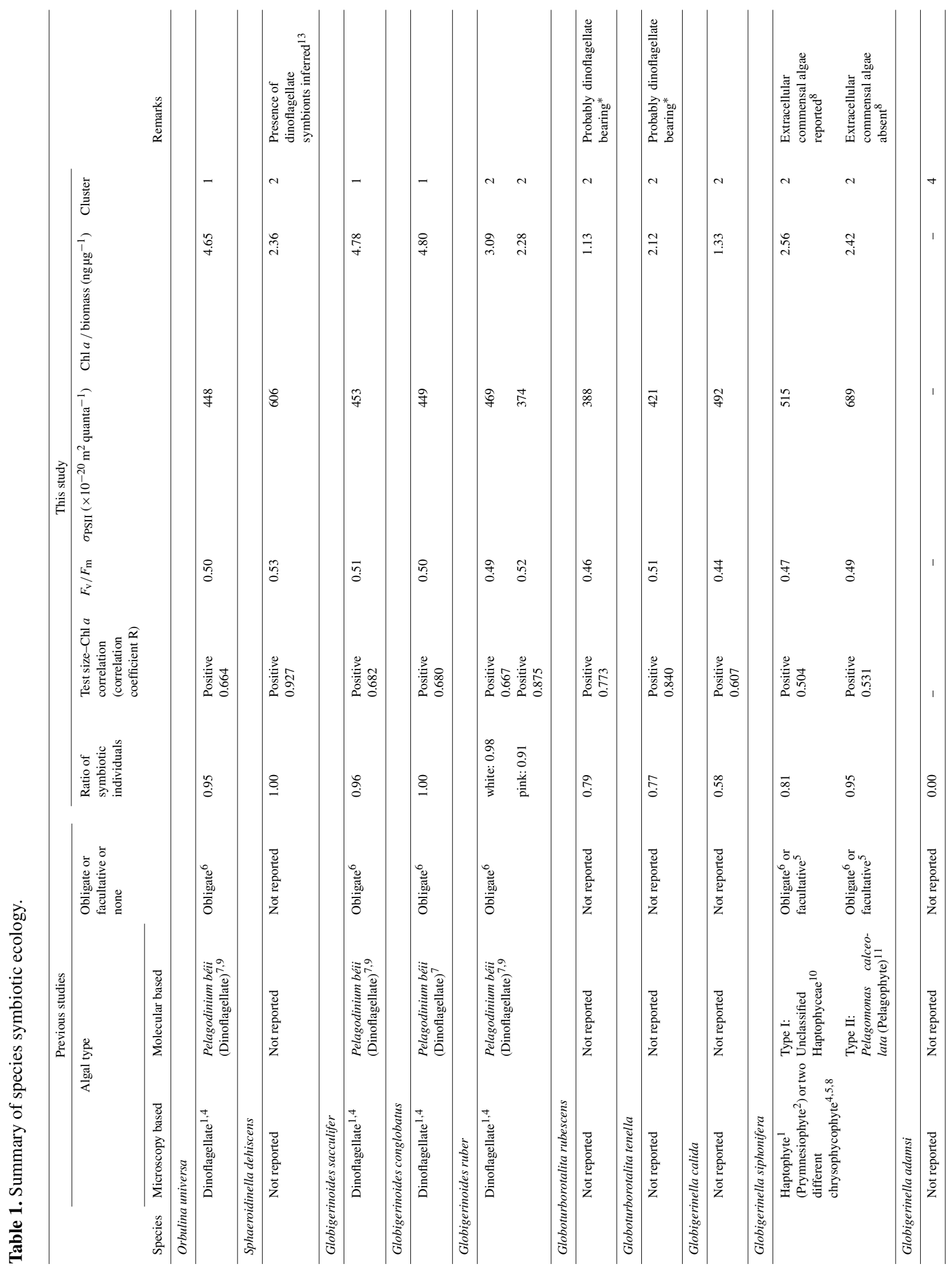




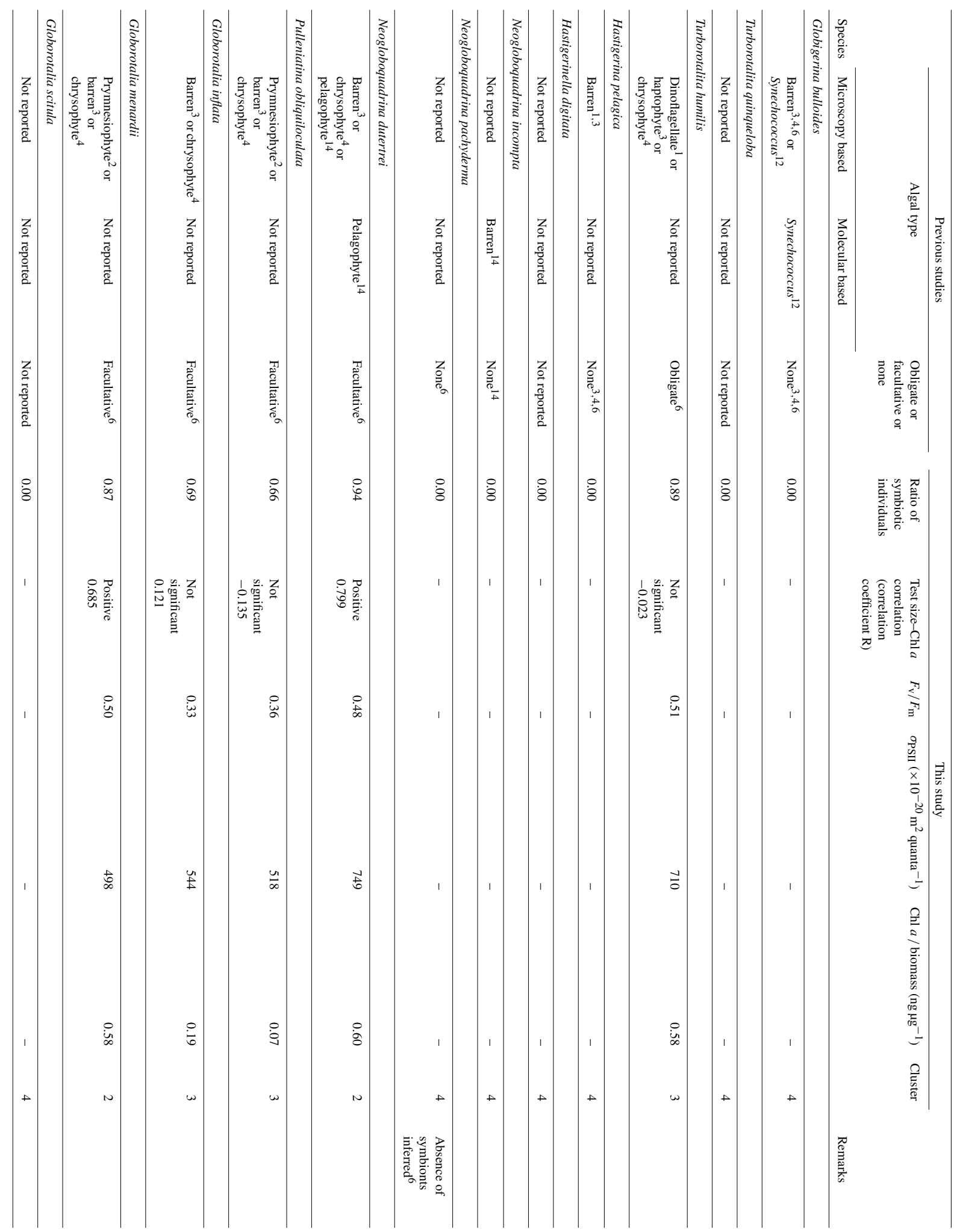

包 
dicated by chlorophyll $a$ content), (2) to qualify the functionality or fitness of symbionts (indicated by photophysiology), (3) to characterize the photosymbiotic features, and (4) to propose a new framework to characterize the photosynthetic activity of modern planktonic foraminifera.

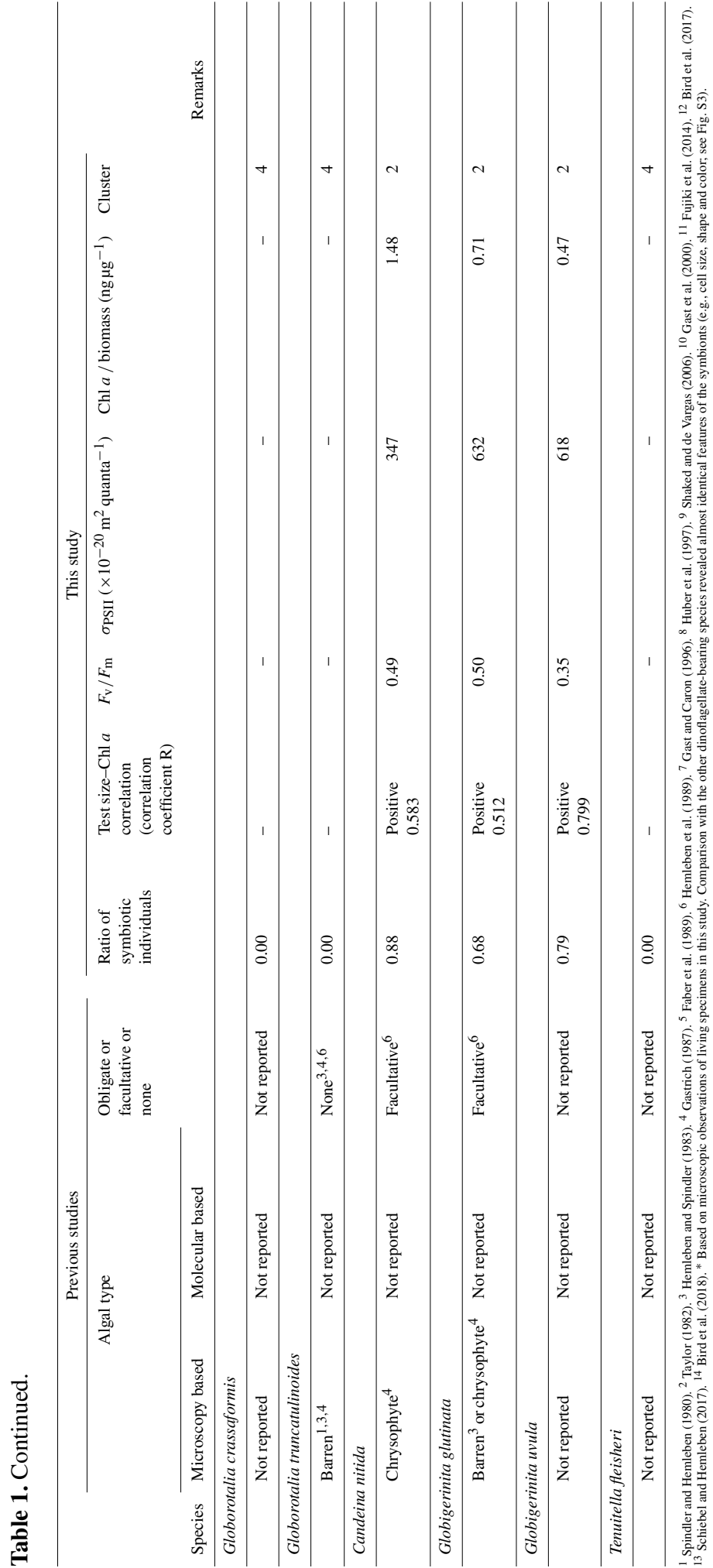

\section{Material and methods}

\subsection{Sampling and identification of morphological species}

Planktonic foraminifera were collected in the central and western Pacific Ocean and the northeastern Atlantic Ocean (Fig. 1). We took samples across much of the Northern Hemisphere tropical-subtropical gradient in both the Pacific and Atlantic oceans in order to get the endemic species and to replicate for the other species. Samples from the Pacific Ocean were taken onboard during the RV Mirai cruises MR13-04 and MR14-02, the RV Kaiyo cruise KY14-09, the RV Shinsei Maru cruise KS-16-9, and the RV Hakuho Maru cruises KH-16-7 and KH-17-4 (Fig. 1a). The samples were collected either by vertical stratified towing (closing ring net or Vertical Multiple Plankton Sampler with $100 \mu \mathrm{m}$ mesh) or by pumped seawater (sampling depth: ca. $5 \mathrm{~m}$ ). The pumped seawater was continuously opened to a $100 \mu \mathrm{m}$ mesh net settled within a water tank to collect specimens as gently as possible. Some specimens were additionally collected from Tsugaru Strait, Sagami Bay, and near Sesoko Island by surface towing and vertical towing with a $100 \mu \mathrm{m}$ mesh net to increase the taxonomic range of our analysis. Samples from the Atlantic were taken onboard during the RV Meteor cruise M140 (Fig. 1b). A multi-closing net system (Multi Plankton Sampler) with a $100 \mu \mathrm{m}$ mesh was used for stratified sampling of the water column. Samples from pumped seawater (sampling depth: ca. $8 \mathrm{~m}$ ) were also collected in the same way as to the Pacific sampling.

Collected specimens were isolated immediately after collection with either brush or Pasteur pipettes into petri dishes filled with $0.22 \mu \mathrm{m}$ filtered or $0.45 \mu \mathrm{m}$ filtered seawater and rinsed several times. Specimens were identified to morphospecies level under a stereoscopic microscope, and the maximum test length (test size) was measured. We consistently measured the maximum test length regardless of the growth stage. Hence for $O$. universa, we measured a trochospiral diameter for pre-spherical juveniles and a sphere diameter for adult specimens. We identified 30 morphospecies from four families (Globigerinidae, Hastigerinidae, Globorotaliidae, and Candeinidae) (Fig. 2). Sphaeroidinella dehiscens was identified only after it thickened its test wall forming cortex during the adult stage under culture; the data we used here were from the very first measurement after collection before the identification. We differentiated the G. ruber white variety and pink variety based on the pigmentation in earlier whorls of the tests. Globigerinella siphonifera was divided 

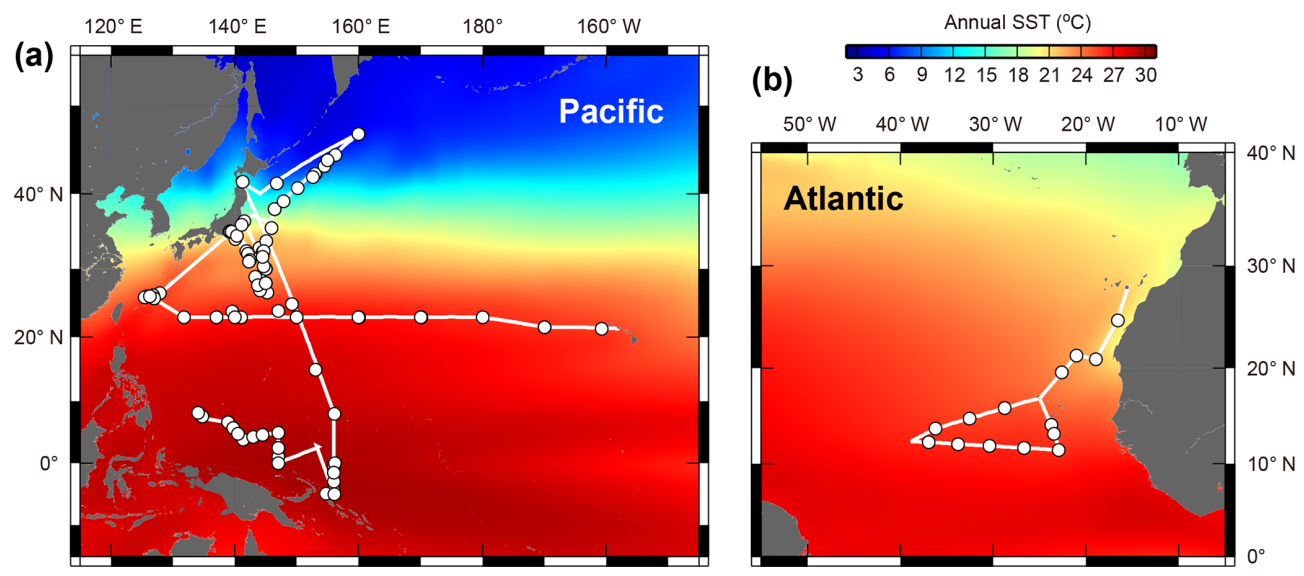

Figure 1. Maps showing the cruise tracks (lines) and the sampling points (circles). (a) Central and western Pacific area and (b) tropical eastern Atlantic area. See Table S1 for detailed sampling information. Annual sea surface temperature (SST) data were from the World Ocean Atlas 2013 (Locarnini et al., 2013).

into two morphotypes (Type I and Type II) based on the criteria described in Faber et al. (1988) and Huber et al. (1997). From among the isolated individuals, viable specimens were selected for analysis with the following criteria: (1) penultimate chamber was filled with cytoplasm, and (2) the specimen was sticky when touched with a brush or the rhizopods were observed under a microscope. Screening for the presence of photosymbiosis was conducted on as many species and specimens as possible, regardless of locality and sampling depth. Photophysiological measurements were carried out only on specimens collected from the upper $100 \mathrm{~m}$ of the water column (corresponding approximately to the photic zone). The specimens were kept individually in a well of a culture dish filled with filtered seawater until the measurement. The duration between the collection and the measurement was no longer than $12 \mathrm{~h}$. During this time, most spinose species recovered their spines.

\subsection{Fast repetition rate fluorometry measurements and photophysiological parameters}

Fast repetition rate (FRR) fluorometry, a kind of active fluorometry, can obtain photophysiological information of hostalgal symbiotic consortia using various parameters of photosystem II (PSII) (Fig. 3). FRR fluorescence transients were measured either using a FRR fluorometer DF-03 or DF-14 (Kimoto Electric Co., Ltd.) (Table S1 in the Supplement). FRR fluorometers generate a series of blue flashlets of an excitation light intensity of $30 \mathrm{mmol}$ quanta $\mathrm{m}^{-2} \mathrm{~s}^{-1}$ with a wavelength of $470 \mathrm{~nm}$ and a $25 \mathrm{~nm}$ bandwidth (DF-03) or a wavelength of $450 \mathrm{~nm}$ and a $10 \mathrm{~nm}$ bandwidth (DF-14). Saturation protocols were consisting of 50 flashlets of $2 \mu \mathrm{s} \mathrm{du}-$ ration at $4 \mu$ s intervals (DF-03) or 100 flashlets of $1 \mu \mathrm{s}$ duration at $2 \mu$ s intervals (DF-14). A fluorescence induction curve based on the biophysical model of Kolber et al. (1998) was numerically fitted to transients of chlorophyll fluorescence to derive PSII parameters. The parameters include minimum fluorescence $\left(F_{0}\right)$, maximum fluorescence $\left(F_{\mathrm{m}}\right)$, variable fluorescence $\left(F_{\mathrm{v}}\left(=F_{\mathrm{m}}-F_{0}\right)\right)$, maximum photochemical efficiency indicating photosynthetic activity $\left(F_{\mathrm{v}} / F_{\mathrm{m}}\right)$, and functional absorption cross section of PSII indicating light-absorption efficiency ( $\left.\sigma_{\text {PSII }}\right)$ (Fig. 3). Before making measurements, it was confirmed for each specimen by stereoscopic microscopy that no visible contamination of algae or particles were present at the test surface or on spines. After 10 min dark adaptation, a specimen was transferred into a quartz glass cuvette with filtered seawater for measurement.

\subsection{Assessment of symbiont possession and parameters characterizing photosymbiosis}

When chlorophyll fluorescence $(F)$ was detected from an individual foraminifera, the status of chlorophyll was categorized based on the detection of variable fluorescence $\left(F_{\mathrm{v}}\right)$. $F_{\mathrm{V}}$ represents fluorescence transients during the saturation process of the reaction centers of PSII. It is detected only when the PSII captures photons and passes the product further through the chain of photosynthetic reactions, i.e., when actively photosynthesizing organisms are present in the specimen. When $F_{\mathrm{v}}$ was not detected, but $F$ value was significantly higher than the background level of the fluorometer, chlorophyll was regarded to be present but non-functional, signifying remnants of phytoplankton prey or possibly phytoplankton in the gut of zooplankton prey. If no $F$ was detected, the specimen had no chlorophyll (Figs. 3 and 4).

When functional chlorophyll was detected in a specimen, then the maximum fluorescence $\left(F_{\mathrm{m}}\right)$ value was used to estimate chlorophyll $a$ (Chl $a$ ) content of the specimen based on a linear relationship between $F_{\mathrm{m}}$ and Chl $a$ (cf. Fujiki et al., 2014; Takagi et al., 2016). A calibration line was established for each FRR fluorometer. A relationship between the Chl $a$ content, an indicator of symbiont biomass, 


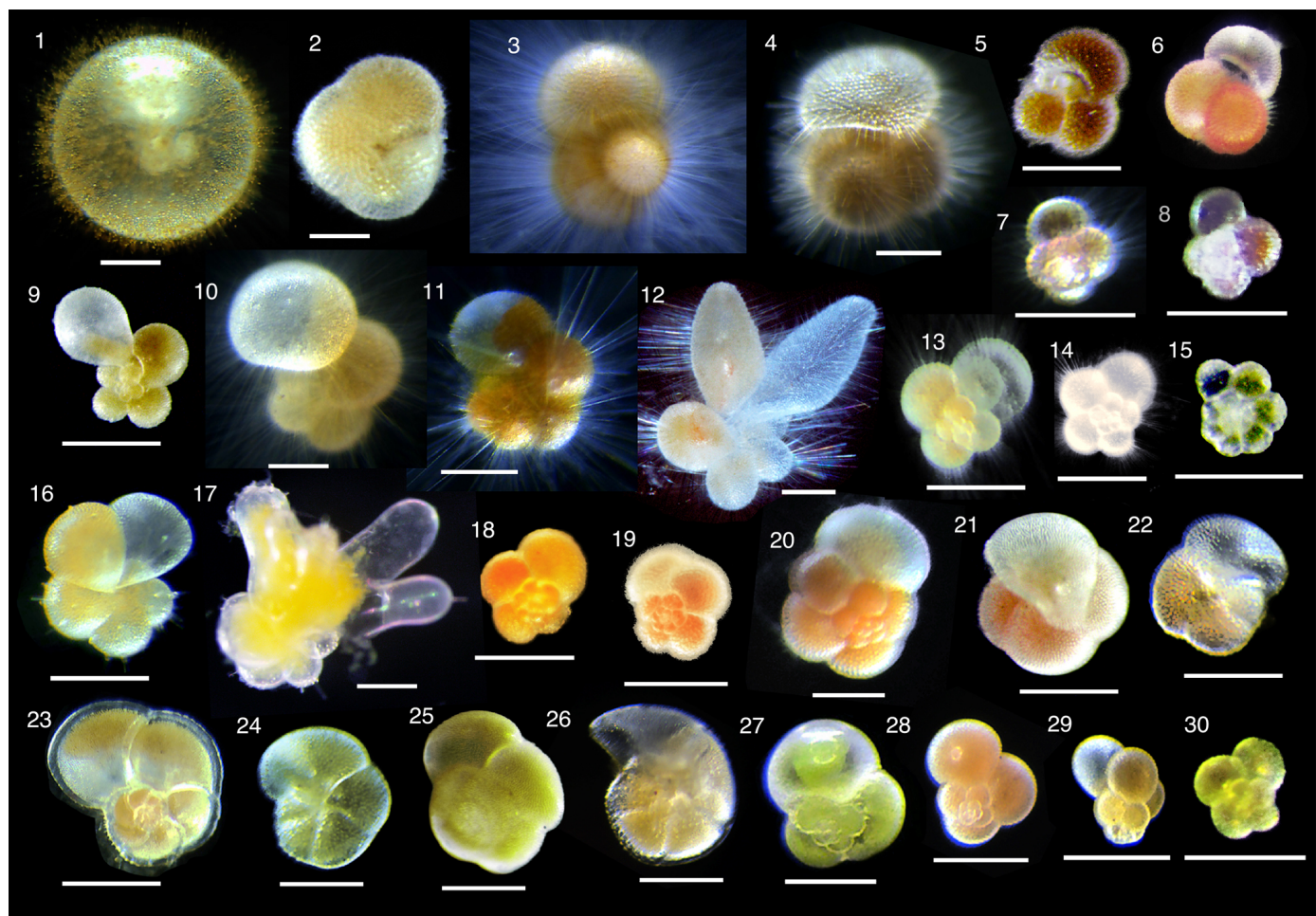

Figure 2. Photomicrographs of representative individuals for species analyzed. (1) Orbulina universa, (2) Sphaeroidinella dehiscens, (3) Globigerinoides sacculifer, (4) Globigerinoides conglobatus, (5) Globigerinoides ruber (white), (6) Globigerinoides ruber (pink), (7) Globoturborotalita rubescens, (8) Globoturborotalita tenella, (9) Globigerinella calida, (10) Globigerinella siphonifera Type I, (11) Globigerinella siphonifera Type II, (12) Globigerinella adamsi, (13) Globigerina bulloides, (14) Turborotalita quinqueloba, (15) Turborotalita humilis, (16) Hastigerina pelagica, (17) Hastigerinella digitata, (18) Neogloboquadrina incompta, (19) Neogloboquadrina pachyderma, (20) Neogloboquadrina dutertrei, (21) Pulleniatina obliquiloculata, (22) Globorotalia inflata, (23) Globorotalia menardii, (24) Globorotalia scitula, (25) Globorotalia crassaformis, (26) Globorotalia truncatulinoides, (27) Candeina nitida, (28) Globigerinita glutinata, (29) Globigerinita uvula, and (30) Tenuitella fleisheri. Scale bars are $200 \mu \mathrm{m}$.

and the foraminiferal test size was then analyzed. To normalize to the size of an individual, Chl $a$ content per protein biomass (Chl $a$ / biomass) was also calculated. The protein biomass was estimated based on species-specific relationships with test size (exponential equation) proposed by Movellan (2013). For species whose test size-biomass relationship was not presented in her study, the protein biomass was estimated based on the relationship established by morphologically similar species (Table S2). As indicators of photosynthetic vitality and light-absorption efficiency of symbionts, photophysiological parameters $F_{\mathrm{v}} / F_{\mathrm{m}}$ and $\sigma_{\mathrm{PSII}}$ were used, respectively.

\subsection{Statistical analysis}

To compare the differences in the parameters (Chl $a /$ biomass, $F_{\mathrm{v}} / F_{\mathrm{m}}$, and $\left.\sigma_{\mathrm{PSII}}\right)$ among species, statistical tests for comparison of differences in medians (Kruskal-Wallis test and post hoc Steel-Dwass test for multiple comparison) were conducted. Species with fewer than 20 specimens were not tested due to the small sample size. Principal component analysis (PCA) was performed to characterize photosymbiotic features of the studied species, based on the four diagnostic variables of photosymbiosis obtained in this study: (1) ratio of symbiont-bearing individuals, (2) correlation coefficient between test size and Chl $a$ content, (3) Chl $a$ content relative to the protein biomass (Chl $a$ /biomass), and (4) $F_{\mathrm{v}} / F_{\mathrm{m}}$ value. Species medians were used for the variables Chl $a /$ biomass and $F_{\mathrm{v}} / F_{\mathrm{m}}$ as representative values (Table 1). In terms of the correlation coefficient of test size-Chl $a$ relationship, negative values were considered as zero. K-means clustering was also performed to categorize photosymbiosis and to visualize the results of the PCA. All the statistical analyses were performed using R ( $\mathrm{R}$ version 3.3.1, $\mathrm{R}$ Core Team, 2016).

\section{Results}

\subsection{Possession of symbionts}

The results of the measurements on all 1266 specimens are shown in Table S1, including sampling locality, date, and the measured parameters. The incidences of each type 

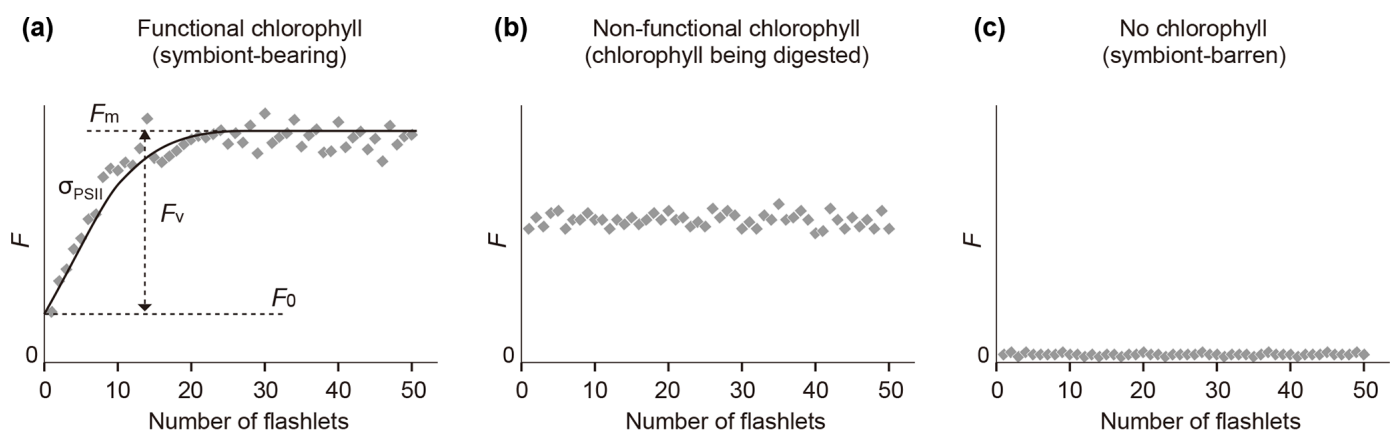

\begin{tabular}{|l|l|l|}
\hline Term & \multicolumn{1}{|c|}{ Definition } & \multicolumn{1}{c|}{ Indication } \\
\hline \hline$F$ & Chlorophyll fluorescence (arbitrary unit) & Presence of chlorophyll \\
\hline$F_{\mathrm{m}}$ & Maximum fluorescence (arbitrary unit) & Chl a content \\
\hline$F_{0}$ & Minimum fluorescence (arbitrary unit) & - \\
\hline$F_{\mathrm{v}}$ & Variable fluorescence $F_{\mathrm{m}}-F_{0}$ (arbitrary unit) & $\begin{array}{l}\text { Presence of functional chlorophyll indicating } \\
\text { the presence of symbionts }\end{array}$ \\
\hline$F_{\mathrm{v}} / F_{\mathrm{m}}$ & Potential photochemical efficiency (dimensionless) & Photosynthetic activity indicating vitality of symbionts \\
\hline$\sigma_{\mathrm{PSII}}$ & $\begin{array}{l}\text { Functional absorption cross section of } \\
\text { PSIl photochemistry }\left(\times 10^{-20} \mathrm{~m}^{2} \text { quanta }{ }^{-1} / \AA^{2} \text { quanta }{ }^{-1}\right)\end{array}$ & Light absorption efficiency \\
\hline
\end{tabular}

Figure 3. Schematic diagram of fluorescence induction curves by fast repetition rate fluorometry and their interpretation. (a) Profile of a symbiotic individual. (b) Profile of a non-functional chlorophyll-bearing individual. (c) Profile of a non-symbiotic individual. Photosystem II parameters used in this study are also listed. All parameters are obtained in dark-adapted states.

of chlorophyll (functional, non-functional, and no chlorophyll) are summarized in Fig. 5. Chlorophyll fluorescence, either functional or non-functional, was detected in 27 out of 30 species. The species G. adamsi, N. incompta, and $N$. pachyderma never showed any evidence for the presence of chlorophyll. Specimens of G. scitula, G. crassaformis, G. truncatulinoides, H. pelagica, $H$. digitata, $G$. bulloides, T. quinqueloba, and T. fleisheri never possessed functional chlorophyll, although many of them contained non-functional chlorophyll. A total of 19 species contained functional chlorophyll and can be considered symbiont bearing: O. universa, S. dehiscens, G. sacculifer, G. conglobatus, G. ruber (white), G. ruber (pink), G. rubescens, G. tenella, G. calida, G. siphonifera Type I, G. siphonifera Type II, T. humilis, P. obliquiloculata, N. dutertrei, G. inflata, G. menardii, C. nitida, G. glutinata, and G. uvula. Among these species, the percentage of symbiont-bearing individuals varied from $100 \%$ (S. dehiscens and G. conglobatus) to $58 \%$ (G. calida). Although the examined specimens included individuals collected at all depths, the percentages of nonfunctional or no-chlorophyll individuals were similar when removing the specimens collected below $100 \mathrm{~m}$ (Fig. S1 in the Supplement). The incidence of symbiotic individuals was not significantly different between the Pacific and Atlantic $(p \gg 0.05$; Fisher's exact test for species with more than 15 individuals in each basin; see Fig. S2). Moreover, the on- togenetic (size) trend in possession of symbionts was not apparent (Fig. 6).

Globoturborotalita rubescens and G. tenella have never been reported to possess symbionts, but we observed ovoid reddish-brown symbionts along with their spines as similarly observed in O. universa, G. ruber, G. conglobatus, and G. sacculifer (Fig. S3). The remaining symbiont-bearing species that have never been reported before were G. calida and G. uvula. Symbionts of these species are treated here as uncharacterized. As a precaution, the convincing symbiontbearing species whose symbionts have not yet been identified by DNA analysis are also treated as uncharacterized: $T$. $h u$ milis, P. obliquiloculata, G. inflata, G. menardii, C. nitida, and G. glutinata (Table 1).

\subsection{Test size-Chl $a$ content relationship, and Chl $a$ / protein biomass}

Out of the 19 species which had functional chlorophyll (symbiont-bearing species), 16 species showed a statistically significant positive correlation between test size and Chl $a$ content ( $p<0.05$, Fig. 6), with Chl $a$ content being a power function of test size. The powers (scaling exponents) of the fitted functions varied from 1.33 (G. tenella) to 3.71 (G. cal$i d a$ ) (Table 2). For the remaining three species, T. humilis, $P$. obliquiloculata, and G. inflata, their test size-Chl $a$ relationships showed no significant correlation (Fig. 6). 
Table 2. Scaling exponents (slopes in Figs. 6 and 10) for relationships between test size and Chl $a$ content. Reduced major axis regression was used to estimate the scaling exponents after logarithmic transformation of the two variables. When the correlation was not significant, the values are not shown. $N$ : the number of specimens used for the analysis. CI: confidence interval.

\begin{tabular}{lrrrr}
\hline Species or morphogroup & $N$ & \multicolumn{3}{c}{ Scaling exponent } \\
\cline { 3 - 5 } & & Best estimate & $2.5 \%$ CI & $97.5 \%$ CI \\
\hline Orbulina universa & 75 & 1.90 & 1.60 & 2.26 \\
Sphaeroidinella dehiscens & 7 & 2.91 & 1.92 & 4.43 \\
Globigerinoides sacculifer & 94 & 3.10 & 2.66 & 3.60 \\
Globigerinoides conglobatus & 18 & 1.83 & 1.25 & 2.68 \\
Globigerinoides ruber (white) & 49 & 2.36 & 1.90 & 2.93 \\
Globigerinoides ruber (pink) & 40 & 2.62 & 2.24 & 3.07 \\
Globoturborotalita rubescens & 15 & 1.59 & 1.09 & 2.30 \\
Globoturborotalita tenella & 10 & 1.33 & 0.87 & 2.04 \\
Globigerinella calida & 11 & 3.71 & 2.10 & 6.56 \\
Globigerinella siphonifera Type I & 61 & 3.57 & 2.85 & 4.47 \\
Globigerinella siphonifera Type II & 53 & 2.89 & 2.28 & 3.66 \\
Turborotalita humilis & 17 & - & - & - \\
Neogloboquadrina dutertrei & 91 & 3.16 & 2.79 & 3.59 \\
Pulleniatina obliquiloculata & 45 & - & - & - \\
Globorotalia inflata & 9 & - & - & - \\
Globorotalia menardii & 144 & 1.84 & 1.63 & 2.08 \\
Candeina nitida & 32 & 3.20 & 2.37 & 4.31 \\
Globigerinita glutinata & 69 & 2.43 & 1.97 & 2.99 \\
Globigerinita uvula & 11 & 2.66 & 1.71 & 4.12 \\
\hline Macroperforate spinose with dinoflagellate & 308 & 2.52 & 2.37 & 2.67 \\
Macroperforate spinose with non-dinoflagellate & 125 & 3.06 & 2.64 & 3.55 \\
Macroperforate non-spinose & 235 & 2.17 & 1.95 & 2.41 \\
Microperforate non-spinose & 112 & 2.61 & 2.30 & 2.95 \\
\hline & & & & - \\
& & & &
\end{tabular}

The ratio of Chl $a$ to protein biomass per individual showed clear differences among species (Fig. 7). Globigerinoides conglobatus, G. sacculifer, and $O$. universa showed significantly higher $\mathrm{Chl} a$ / biomass values (species

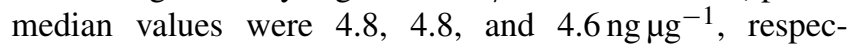
tively), and $P$. obliquiloculata showed the lowest median

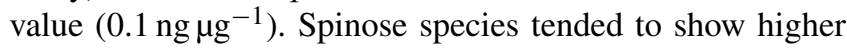
Chl $a$ / biomass values than non-spinose species.

\subsection{Photophysiological state}

Overall, $F_{\mathrm{v}} / F_{\mathrm{m}}$ values tended to be high in dinoflagellatebearing species (species median values 0.46-0.53) (Fig. 8a). Amongst all 19 symbiont-bearing species, $F_{\mathrm{v}} / F_{\mathrm{m}}$ value was highest in $S$. dehiscens (0.53) and lowest in $G$. inflata (0.33). Species to species comparison showed that $P$. obliquiloculata alone showed significantly lower $F_{\mathrm{v}} / F_{\mathrm{m}}$ values $(p \ll 0.01)$.

On the other hand, $\sigma_{\text {PSII }}$ was relatively low in dinoflagellate-bearing species (median values 374-606 $\times$ $10^{-20} \mathrm{~m}^{2}$ quanta ${ }^{-1}$ ) and high in pelagophyte-bearing species (median values 618-749 $\times 10^{-20} \mathrm{~m}^{2}$ quanta $^{-1}$ ) (Fig. 8b). The highest and lowest $\sigma_{\text {PSII }}$ values in the median were recorded for $N$. dutertrei $\left(749 \times 10^{-20} \mathrm{~m}^{2}\right.$ quanta $\left.^{-1}\right)$ and $C$. nitida $\left(347 \times 10^{-20} \mathrm{~m}^{2}\right.$ quanta $\left.^{-1}\right)$, respectively. Based on the statis- tical testing of the species to species difference in medians, $N$. dutertrei and $G$. siphonifera Type II (pelagophyte bearing) showed no difference $(p=0.79)$ and were associated with the highest $\sigma_{\text {PSII }}$ value. Globigerinoides ruber (pink) alone showed significantly lower $\sigma_{\text {PSII }}$ values than the other dinoflagellate-bearing species $(p \ll 0.01)$, and the value was comparable to that of $C$. nitida $(p=1.0)$.

\subsection{Principal component analysis and clustering}

To characterize photosymbiotic features, all studied species were tested for PCA with the four diagnostic variables of photosymbiosis: (1) ratio of symbiont-bearing individuals, (2) correlation coefficient between test size and Chl $a$ content, (3) Chl a content relative to the protein biomass (Chl $a$ / biomass), and (4) the $F_{\mathrm{v}} / F_{\mathrm{m}}$ value (Table 1 ). The first principal component (PC1) alone accounted for $84.2 \%$ of the total variance, and the second principal component (PC2) accounted for $10.2 \%$ (Fig. 9). In the PC1 score, the loading coefficient was positive for all variables related to photosymbiosis used in the analysis (0.96 for the ratio of symbiont-bearing individuals, 0.91 for the positive correlation coefficient of test size-Chl $a$ content relationship, 0.96 for the $F_{\mathrm{v}} / F_{\mathrm{m}}$ median value, and 0.82 for the Chl $a$ content 


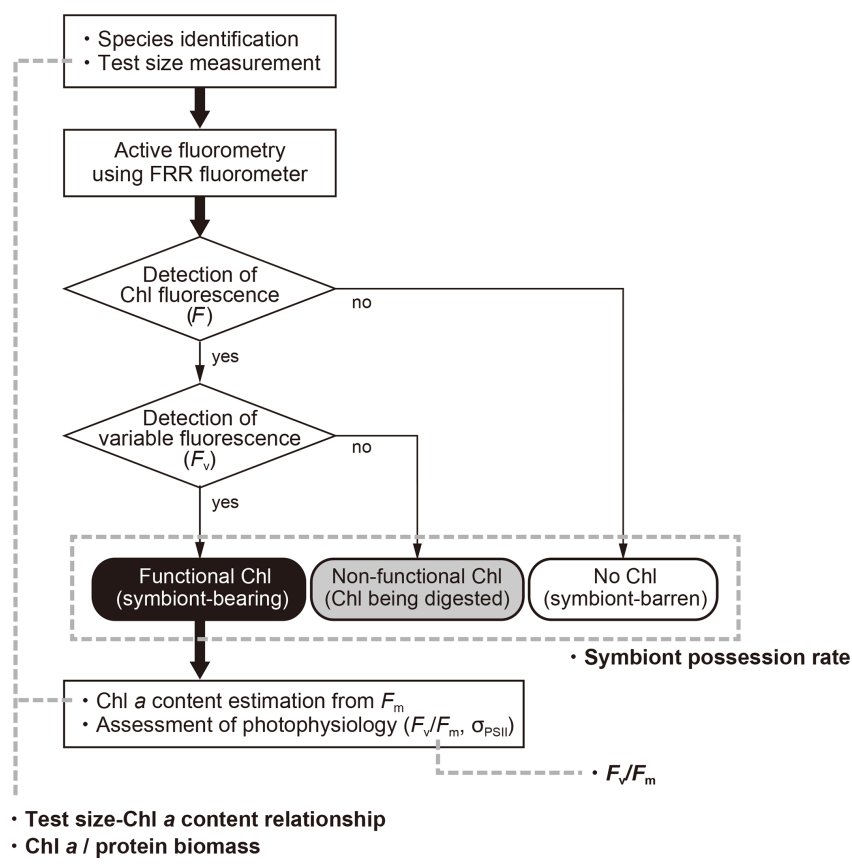

Figure 4. Workflow of this study and four indices used to characterize photosymbiosis. Firstly, individual specimens were identified to morphospecies level, measured for the test size, and analyzed with active fluorometry to check the functionality of chlorophyll. Based on the fluorescence results, intracellular chlorophyll types (status) were categorized into three groups: functional chlorophyll, non-functional chlorophyll, and no chlorophyll. When chlorophyll was functional, the content of Chl $a$ per individual and the photophysiological parameters were analyzed. Finally, four indices in bold (symbiont possession rate, test size-Chl $a$ relationship, Chl $a$ / biomass and $F_{\mathrm{V}} / F_{\mathrm{m}}$ ) were derived and used for the characterization of photosymbiosis (see text for details).

relative to protein biomass). Considering the high contribution to explaining the total variance and the positive loading for the four variables, the PC1 score represented well the photosymbiotic characteristics among the foraminiferal species. In fact, the cluster analysis confirmed that four clusters of species were separated along the PC1 score. The lowest PC1 score $(-2.2)$ was recorded by non-symbiotic species (cluster 4). The distribution of species along the PC1 score was relatively wide for clusters 2 and $3(0.7-2.2$ and $-0.6-$ 0.2 , respectively), whereas it was almost the same for cluster 1 with the highest score between 2.3 and 2.5. Clusters 1 and 2 consisted of the species with significant positive correlations between test size and Chl $a$ content. Cluster 1 was separated from cluster 2 primarily due to its distinctly high PC2 score. The PC2 was characterized by Chl $a$ content per protein biomass (Chl $a$ / biomass), which exclusively had a positive loading (0.57). Three species within cluster $1, G$. conglobatus, G. sacculifer, and $O$. universa, were revealed to have significantly high Chl $a$ / biomass, as represented in Fig. 7. Cluster 2 consisted of 13 species which showed the

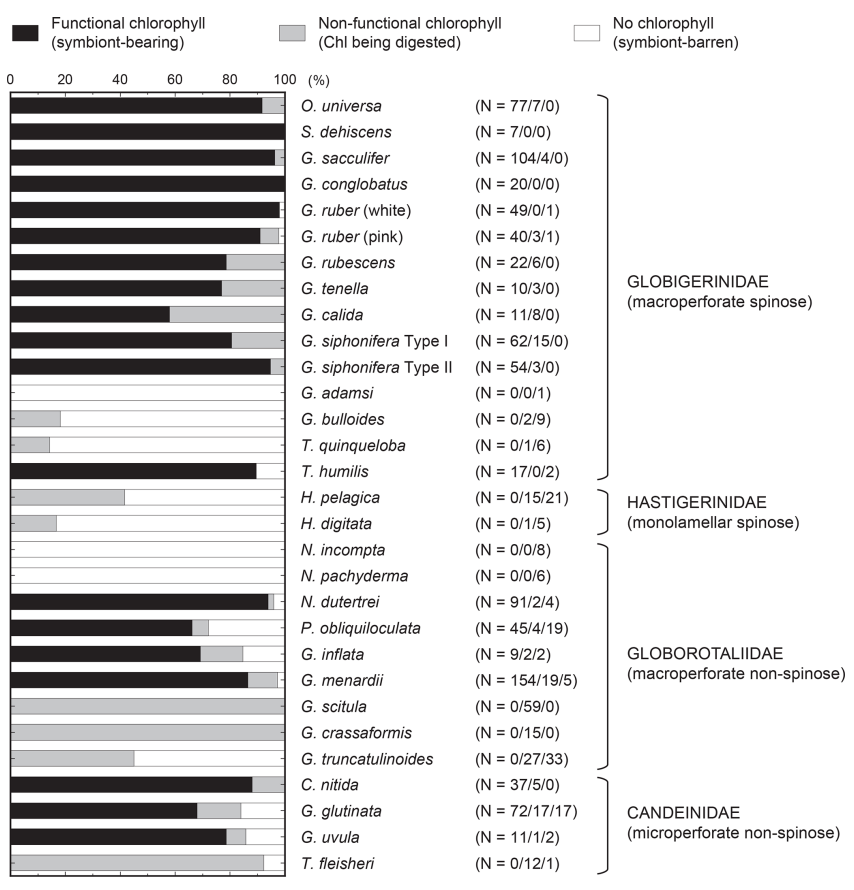

Figure 5. Summary of categorization of intracellular chlorophyll. The functionality of chlorophyll indicates the presence of symbionts. The numbers of specimens for the three categories are represented in parentheses as follows: functional chlorophyll / nonfunctional chlorophyll/no chlorophyll. The percentage of functional chlorophyll is essentially the same as the symbiont possession rate used as a variable to characterize photosymbiosis (see text for details).

widest distribution along both PC1 and PC2 axes. Within cluster 2, the non-spinose species tended to show lower PC1 and PC2 scores compared to the spinose species. Cluster 3 consisted of three species: T. humilis, $P$. obliquiloculata, and $G$. inflata. They were the species that possessed symbionts in most cases but were without significant positive correlation in the test size-Chl $a$ relationship. Overall, the clusters and the PC1 score depicted a clear tendency of photosymbiosisrelated features of the species.

\section{Discussion}

\subsection{Characteristics and a new framework of planktonic foraminiferal photosymbiosis}

The cluster analysis using photosymbiotic variables shows that 30 species fall into four groups, and features relevant to the cluster structure are extracted by PCA (Fig. 9). Cluster 4 is a group of non-symbiotic species. Of the 11 species in this group, six species were tested on their photosymbiosis for the first time and were revealed to be non-symbiotic: G. adamsi, T. quinqueloba, H. digitata, G. scitula, G. crassaformis, and T. fleisheri. An interesting feature of this 

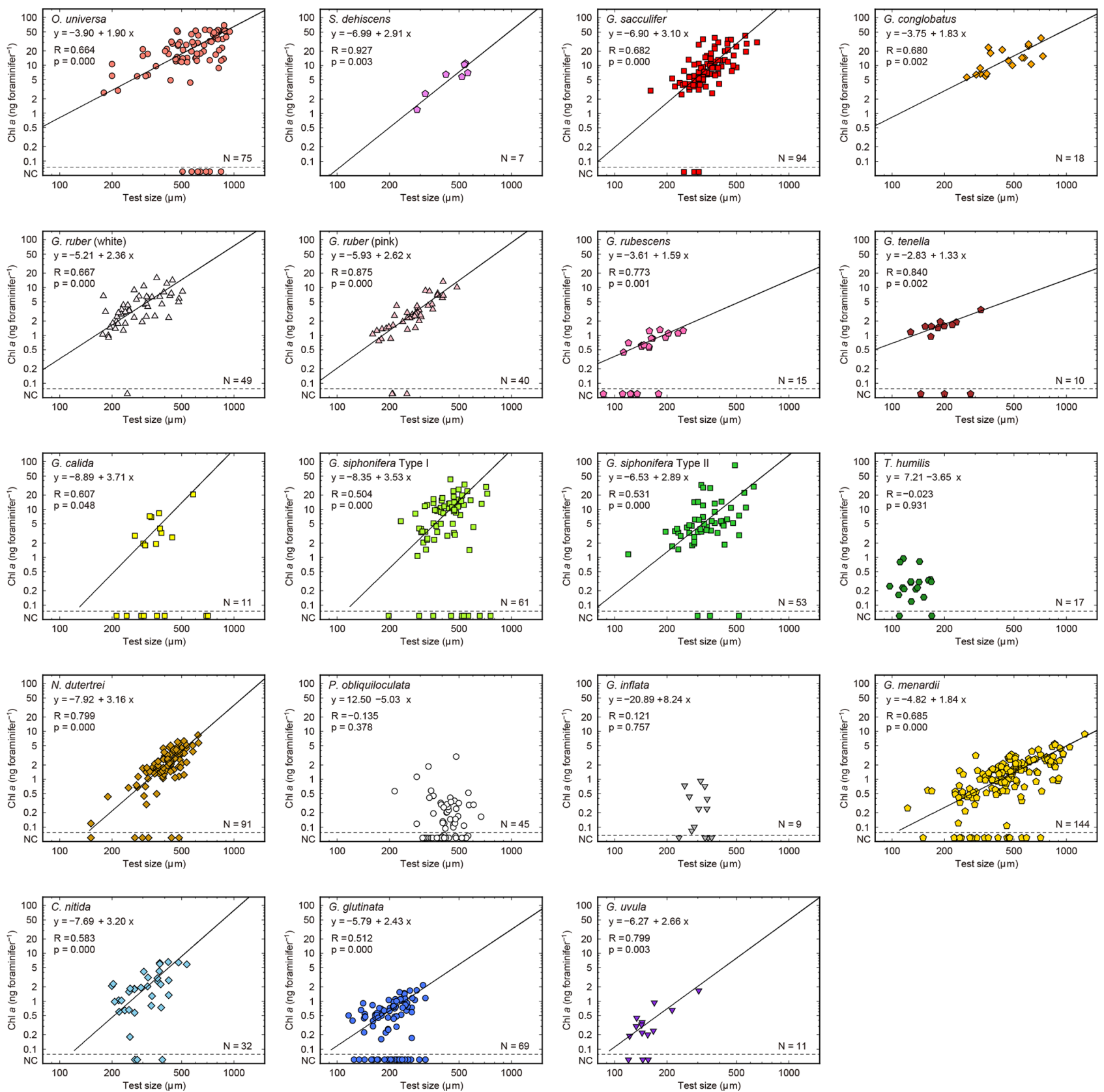

Figure 6. Relationships between test size and Chl $a$ content for each species. Lines represent reduced major axis regression ( $y$ represents $\log (\mathrm{Chl} a)$, and $x$ represents the $\log ($ test size)). Specimens with no chlorophyll and non-functional chlorophyll (NC) are plotted at the bottom of each panel to show their test size information (these data are not used for the regression analysis). R: Pearson's correlation coefficient; $p$ : $p$ value; $N$ : number of specimens with functional chlorophyll (i.e., with symbionts). For $O$. universa, specimens smaller than $400 \mu$ m are a pre-spherical trochospired test diameter, and those larger than $400 \mu \mathrm{m}$ are a sphere diameter (see Table S1).

group is that many species possess non-functional chlorophyll (Fig. 5). For example, all specimens in G. scitula and $G$. crassaformis have a certain amount of chlorophyll inside, but it is always non-functional and likely derived from prey. The occurrence of fresh (fluorescent) chlorophyll in these species is surprising, considering that most of these specimens were collected from a water depth below $300 \mathrm{~m}$ (Table S1), where the chlorophyll concentration is low. They might incorporate sinking aggregates of phytoplankton remains as food (e.g., Anderson et al., 1979; Spindler et al., 1984), and chlorophyll or chloroplast itself might have remained undigested, resulting in non-functional chlorophyll. It is even reported that non-spinose deeper-dwelling foraminifera are often found attached or embedded within marine snow and organic partic- 


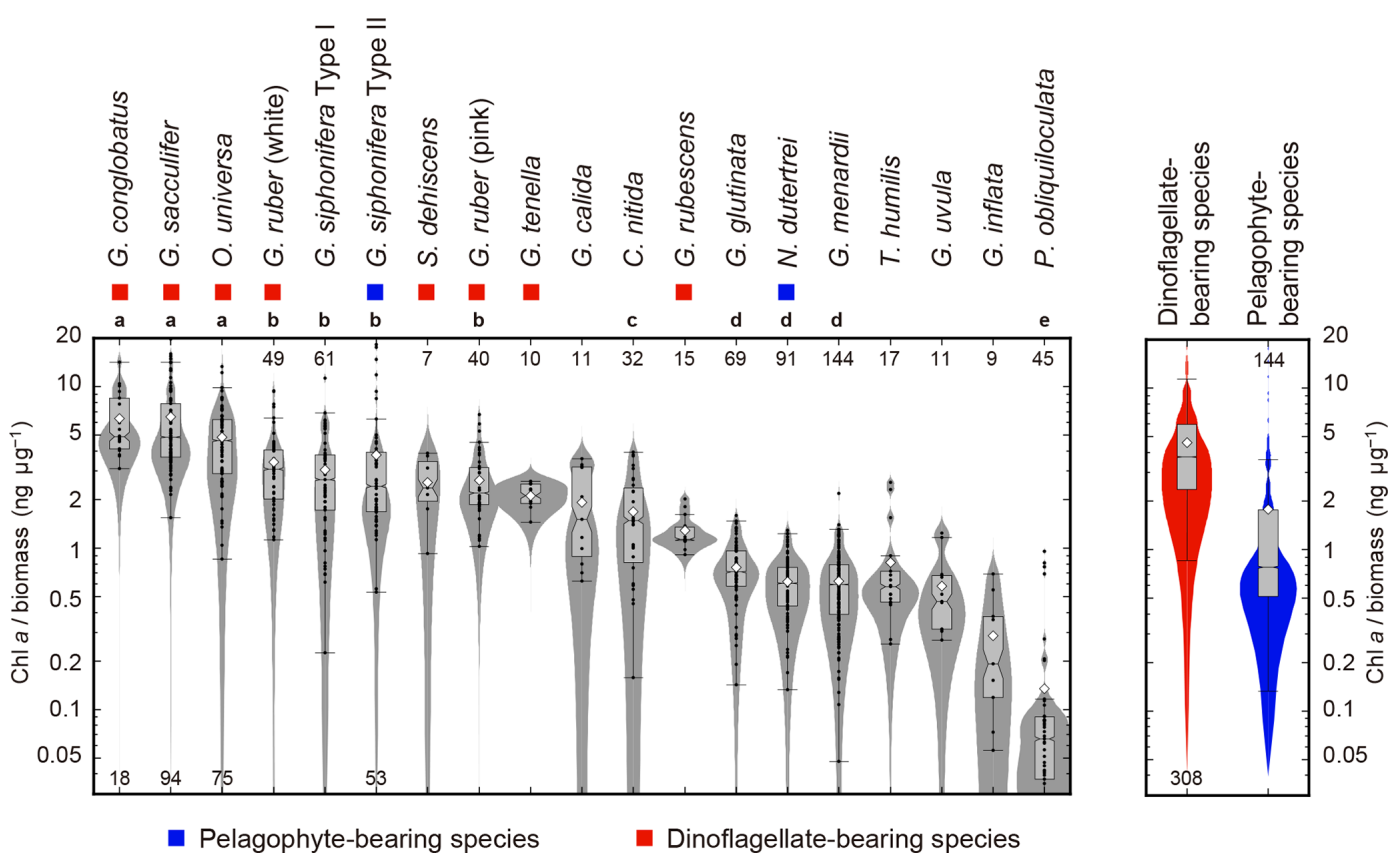

Figure 7. Ratios of $\mathrm{Chl} a$ content (ng foraminifer ${ }^{-1}$ ) to protein biomass ( $\mu$ g foraminifer ${ }^{-1}$ ) of 19 symbiont-bearing species. Dots represent individual data sampled from the upper $100 \mathrm{~m}$ water depth. Box plots represent first and third quartiles as hinges, and the midlines represent medians with notches representing the $95 \%$ confidence intervals of the medians. Means are also represented with open diamonds. Values which lie more than 1.5 times the length of the box from either end of the box are considered as outliers. Violin plots show the distributions as kernel density estimations. Numbers at either end of the panel are the sample size for each species. Species with more than 20 specimens were used for statistical testing (Kruskal-Wallis test for comparison of differences in medians, and post hoc Steel-Dwass test for multiple comparison, $p<0.05$ ). Species with the same letter were not significantly different. Color symbols represent the difference of symbiotic algae (see Table 1). Note that the data are represented on a logarithmic scale.

ulates (Fehrenbacher et al., 2018). We frequently observed a similar behavior or situation during the isolation of collected specimens. Such probable microhabitats, mainly consisting of phytoplankton debris, would facilitate the incorporation of non-functional chlorophyll. Hastigerina pelagica are known to show vertical depth segregation among the genotype (Weiner et al., 2012). It has been speculated that such segregation might be related to their possession of symbionts (e.g., Huber et al., 1997; Seears et al., 2012). Though our study did not identify their genotype, it revealed that this species never possessed symbionts even when collected from a more shallow water depth $(<100 \mathrm{~m})$. A recent study showed that $G$. bulloides type IId possessed cyanobacterial symbionts (Bird et al., 2017). By using our fluorescence technique, chlorophyll fluorescence of cyanobacteria should also be detectable although the most effective wavelength of the fluorescence is slightly different. In fact, two specimens of this species show possession of chlorophyll, yet they are nonfunctional (Table S1). This might indicate that possession of cyanobacterial symbionts may be a genotype dependent, regional, or a seasonal specific phenomenon.

Five species are newly confirmed as symbiotic based on the functionality of chlorophyll: S. dehiscens, G. rubescens, G. tenella, G. calida, and G. uvula. Clusters 1 and 2, in- cluding the above five species, showed relatively high rates of possession of symbionts and exclusively showed significant positive correlations between the test size and Chl $a$ content (Figs. 6 and 10). It was previously revealed that $G$. sacculifer and G. siphonifera Type II showed positive correlations between test size and Chl $a$ content (Takagi et al., 2016). Similarly, O. universa has been demonstrated to have a positive relationship between test size and symbiont number on a logarithmic scale (Spero and Parker, 1985, Fig. S4). The capability of cell divisions of symbionts cannot be determined from our active fluorescence-based study, but the significant positive correlation can be a strong indication for the growth of the symbiont population inside the host foraminifera. Hence, in addition to the high percentage of symbiont-bearing individuals in a species, such strong positive correlation may indicate a persistent relationship of photosymbiosis through their lifetime. Moreover, G. conglobatus, G. sacculifer, and O. universa (cluster 1) should have the potential to support more photosynthesis due to the higher content of $\mathrm{Chl} a$ per protein biomass (Fig. 7).

Clusters 1 and 2 include well-studied symbiotic species such as $O$. universa, G. ruber, G. sacculifer, and G. siphonifera, which were previously reported to be in obligate symbiosis (Hemleben et al., 1989). Amongst facultative sym- 

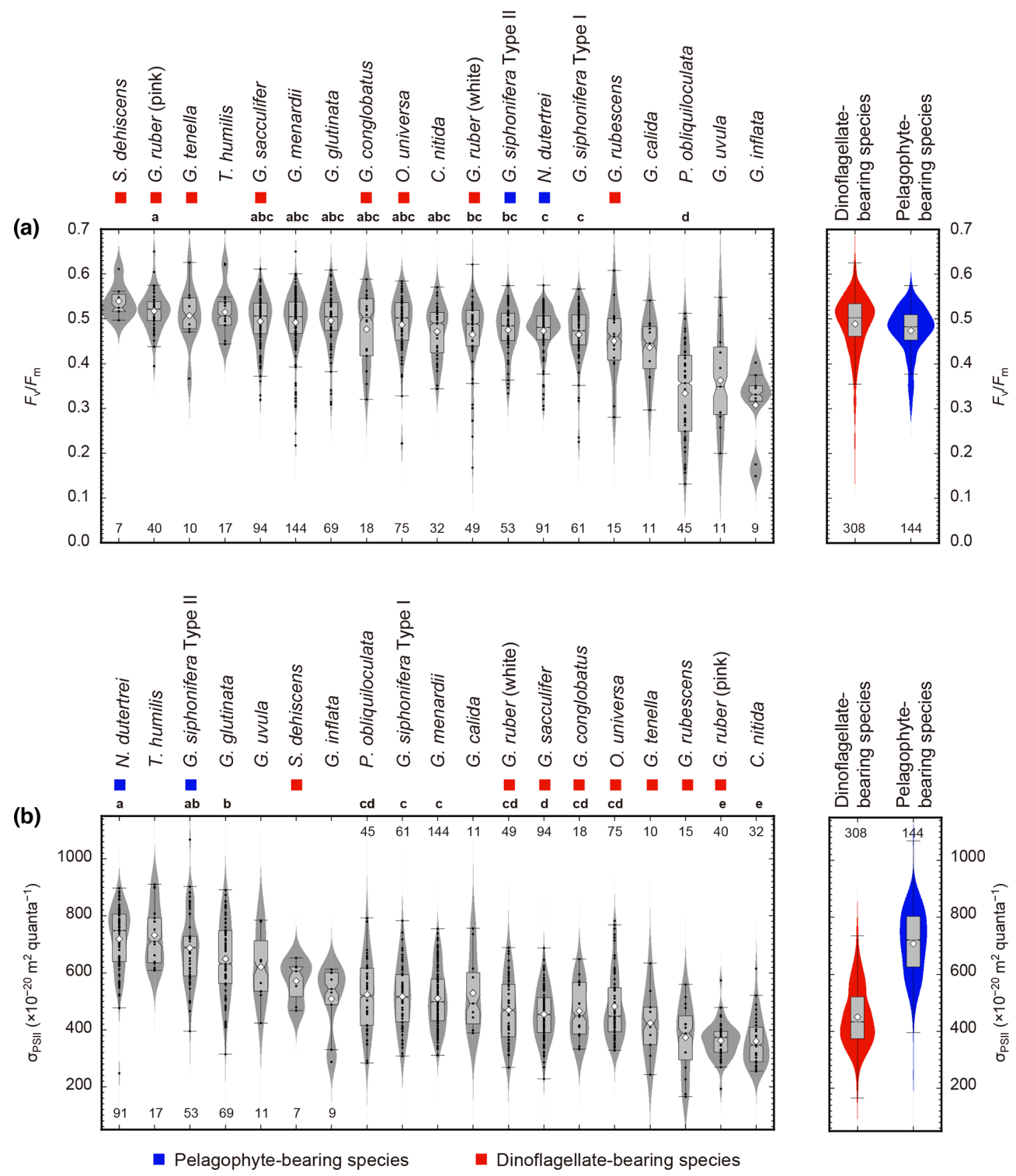

Figure 8. Photophysiological parameters of 19 symbiont-bearing species. (a) $F_{\mathrm{V}} / F_{\mathrm{m}}$ and (b) $\sigma_{\mathrm{PSII}}$. Dots represent individual data sampled from the upper $100 \mathrm{~m}$ water depth. Box plots represent first and third quartiles as hinges, and midlines represent medians with notches representing the $95 \%$ confidence intervals of the medians. Means are also represented with open diamonds. Values which lie more than 1.5 times the length of the box from either end of the box are considered as outliers. Violin plots show the distributions as kernel density estimation. Numbers at either end of the panels are the sample size for each species. Species with more than 20 specimens were used for statistical testing (Kruskal-Wallis test for comparison of differences in medians, and post hoc Steel-Dwass test for multiple comparison, $p<0.05$ ). Species sharing the same letter were not significantly different. Color symbols represent the difference of symbiotic algae (see Table 1).

biotic species inferred in previous studies, $N$. dutertrei, $G$. menardii, C. nitida, and G. glutinata are revealed to have the persistent symbiotic relationships based on our test sizeChl $a$ correlation analysis. In this study, not only the so-far called "facultative" symbiotic species, but also most species were sometimes found without symbionts (all species except for $S$. dehiscens and $G$. conglobatus includes specimens with non-functional chlorophyll, Fig. 5). It was repeat- edly observed that $G$. sacculifer and $G$. siphonifera digest their symbionts prior to gametogenesis (e.g., Bé et al., 1983; Faber et al., 1988; Takagi et al., 2016). Thus, symbiontbarren individuals could be present in the adult stage. However, the size of such symbiont-barren specimens recognized in this study was not necessarily large (Fig. 6). We speculate that these small specimens were in an unhealthy condition and going to die. In any case, the percentage of symbiont- 
(a)

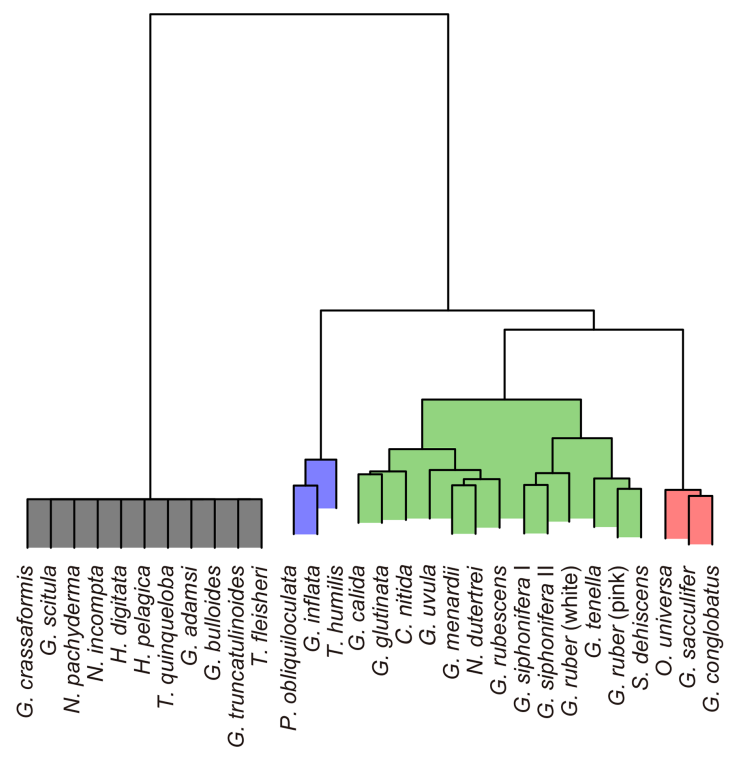

(b)

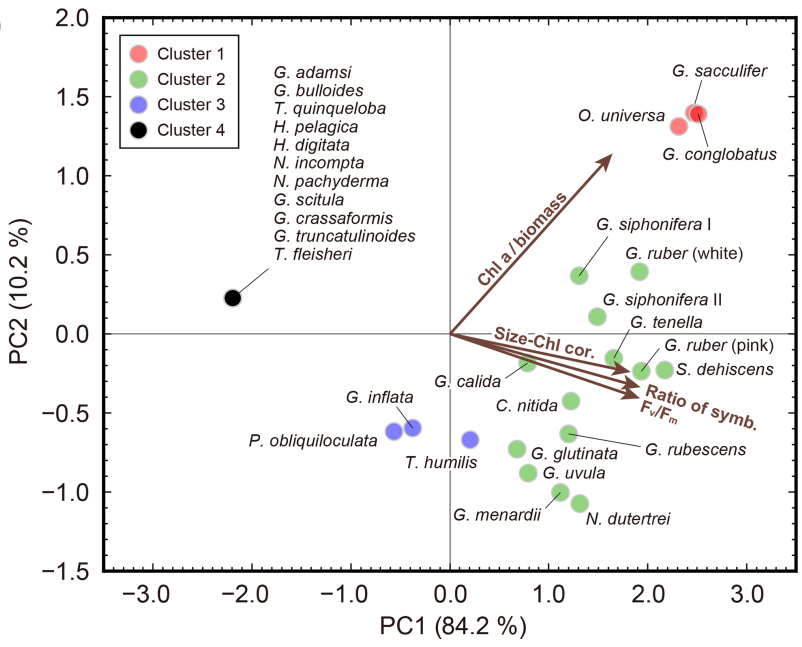

Figure 9. Results of cluster analysis and principal component analysis. (a) Cluster dendrogram obtained using Ward's method. (b) Biplot of principal component analysis. The colors of the symbols correspond to the four clusters. Vectors indicate the direction and strength of each variable to the overall distribution. The first axis explains $84.2 \%$ of the variation and the second axis $10.2 \%$ of the variation. Chl $a$ / biomass: Chl $a$ content per protein biomass estimated from test size of individuals; Size-Chl cor.: correlation coefficient of test size-Chl $a$ content relationship as an indicator of the persistence of symbionts; Ratio of symb.: ratio of symbiotic individuals; $F_{\mathrm{v}} / F_{\mathrm{m}}$ : median $F_{\mathrm{v}} / F_{\mathrm{m}}$ value.

barren individuals in this group was small. We think the presence of symbiont-barren specimens in symbiont-bearing species, unless it is dominant, is not critical to describe the nature of photosymbiosis (i.e., conventional categorization of obligate or facultative symbiosis). Rather, the presence of such symbiont-barren individuals in these groups has led to the confusion in earlier works that placed some of these species into the facultative category. Nevertheless, the ratio of symbiont-bearing individuals may overall reflect the ecological differences among species such as the persistence of symbiosis or the dependence on phototrophy that can quantitatively represent photosymbiosis.

Cluster 3 (P. obliquiloculata, G. inflata, and T. humilis) has intermediate features between persistent symbiosis (cluster 1 and 2) and non-symbiosis (cluster 4). Species do possess symbionts and can be called symbiotic species, but the significant correlation in test size-Chl $a$ relationship, which is common in clusters 1 and 2, is absent (Figs. 5 and 6). It indicates that a larger sized host does not necessarily require more algae, or the algae could not persistently reside in their host to increase their biomass; in other words, the symbiosis is transient. Pulleniatina obliquiloculata and G. inflata are non-spinose species, whose eating habits are reported to be primarily herbivorous (Anderson et al., 1979; Spindler et al., 1984). We hypothesize that they can be temporarily symbiotic when foraminifera maintain certain algae for some time, keeping them undigested and keeping their photosynthetic capability to provide photosynthates. Regardless of the role of the algae, i.e., symbionts or prey, when all the algae are digested, the foraminifera become temporarily chlorophyll barren. If the symbionts do not increase inside the host, the $\mathrm{Chl} a$ content of a specimen is regulated by the incorporation frequency or rate of algal cells and their residence time inside the host (i.e., a balance between incorporation and digestion). This behavior is similar to what is known for the benthic species with kleptoplasts (e.g., Bernhard and Bowser, 1999; Pillet et al., 2011); these are actively harvested and are functional but wear off with time and have to be replenished. A digestion experiment involving these species, therefore, would be interesting to perform in the future in order to test the hypothesis, and FRR fluorometry can also be used in such culturing studies. Together with $P$. obliquiloculata and G. inflata, T. humilis, which was previously inferred as an obligate symbiotic species (Hemleben et al., 1989), falls into cluster 3, which represents such transient symbiosis. However, caution should be paid to the narrow size range of $T$. humilis that we analyzed, which might have caused the low correlation in test size-Chl $a$ relationship (Fig. 6). In addition, the specimens were mostly with 13-15 chambers and probably in their adult stage. In this respect, since a sufficient size range of specimens with a variety of ontogenetic stages were not covered, it is difficult to strongly conclude that symbiosis in $T$. humilis is not persistent. The $F_{\mathrm{v}} / F_{\mathrm{m}}$ value of this species (0.51 in median) is clearly higher compared to the other two species in cluster 3 ( 0.36 for $P$. obliquiloculata and 0.33 for G. inflata). Besides, the possession of symbionts by this species is $89 \%$, which is higher than the other two species (66\% for P. obliquiloculata and $69 \%$ for G. inflata). We, therefore, interpret that $T$. humilis has established more persistent symbiosis compared to $P$. obliquiloculata and $G$. inflata. 

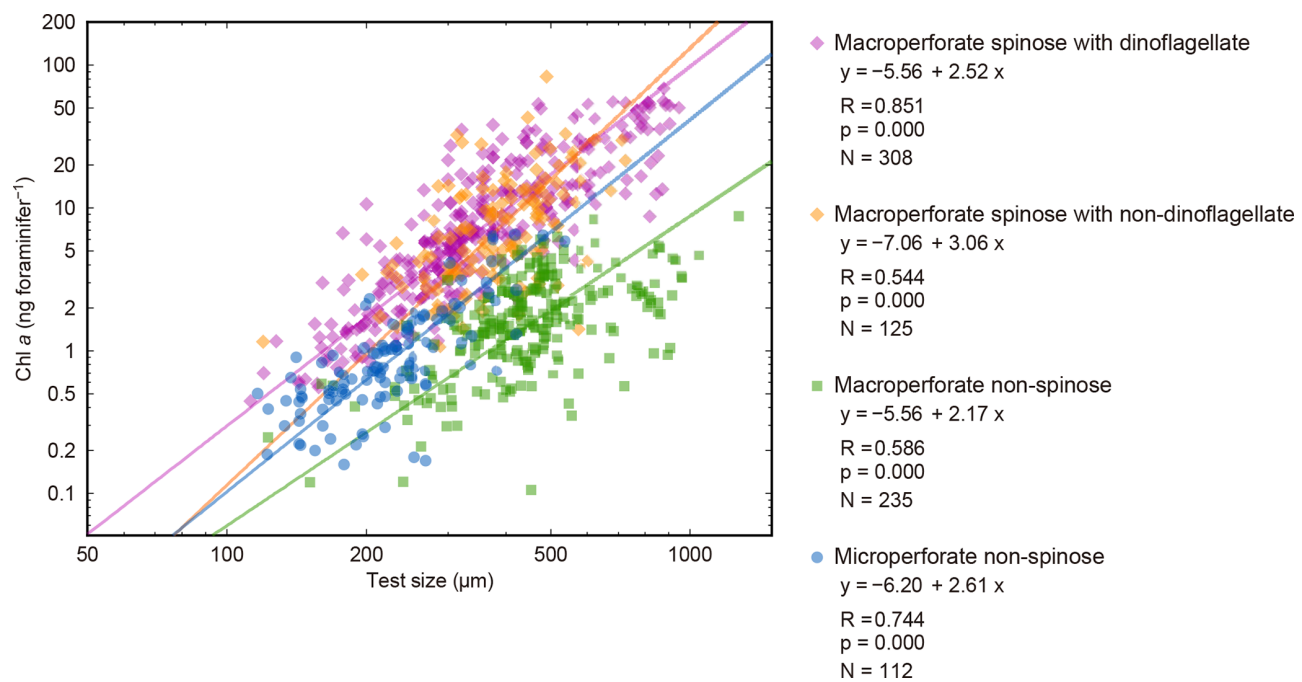

Figure 10. Relationships between test size and Chl $a$ content for four groups. The 16 species with significant test size-Chl $a$ correlation were used. Lines represent reduced major axis regression ( $y$ represents $\log (\mathrm{Chl} a)$, and $x$ represents $\log ($ test size $)$ ). $R$ : Pearson's correlation coefficient; $p: p$ value; $N$ : number of specimens with functional chlorophyll (with symbionts). Note that the groups do not correspond to the clusters in Fig. 9.

Here, considering the above characterization of photosymbiosis, we propose a new framework of planktonic foraminiferal photosymbiosis (Fig. 11). As previously suggested in Stoecker et al. (2009), we also think photosymbiosis can be regarded as a spectrum from absolute nonsymbiosis (heterotrophy) to more robust symbiosis (higher extent of acquired phototrophy or mixotrophy), which ends with a permanent plastid endosymbiosis seen in autotrophs. Each foraminiferal species that possesses symbionts can be located somewhere in between phototrophy and heterotrophy (a certain extent of mixotrophy, Fig. 11). Since the PC1 score well represents the photosymbiotic characteristics, it is suitable as a quantitative indicator of the level of photosymbiosis. Therefore, we aligned the species along with the PC1 score scale in the conceptual diagram (Fig. 11). In this diagram, the necessity of photosymbiosis, i.e., whether the relationship is essential for the host survival, is not considered since we cannot go into a detailed interactional relationship with our method. A recent study using a ${ }^{13} \mathrm{C}$ pulsechase experiment of $O$. univers $a$, subsequent subcellular microimaging, and elemental analysis revealed the fate of assimilated carbon by the symbionts (LeKieffre et al., 2018). They showed a line of evidence of substance transfer from the symbionts to the host and their tight interrelationship. Considering their results for $O$. universa, it is speculated that G. conglobatus and G. sacculifer with higher PC1 scores than $O$. universa should have a similar or even tighter interaction in their symbiotic system. If a similar experiment can be conducted for species with low PC1 scores, especially for G. inflata and P. obliquiloculata whose mode of symbiosis is expected to be different, the information of the internal phe- nomena can be added, which will provide insight about the necessity of photosymbiosis.

An important point here is that this spectrum allows us to gain an overview of the relative strength of photosymbiosis among species and across various families of planktonic foraminifera such as Globigerinidae, Globorotaliidae, and Candeinidae. The relative ordination may be amended by further exploration in the future, but we believe our thorough investigation can shed light on the species-specific differences in the nature of photosymbiosis in planktonic foraminifera. This would be a solid basis to help us to think about evolutionary aspects of photosymbiosis, its role in the earth system history, and possible effects on test geochemistry.

\subsection{Size scaling of Chl $a$ content in symbiotic foraminifera}

The significant positive correlation between test size and Chl $a$ content (Figs. 6 and 10) shows the increasing number of symbionts with host size and shows a quantitative relationship between the host and symbionts based on their scaling exponent (Table 2). In theory, the size scaling exponent of 3 means that the dependent variable increases proportionally to the volume development. If the test shape is less spherical, as in the case of G. menardii, the exponent should be smaller and approaching 2 . Alternatively, when the test volume does not reflect the cytoplasm volume (the increase in the cytoplasm is less than that of the test volume), such as adult spherical specimens of $O$. universa, the scaling exponent results in relatively small values. The fact that all 16 species show a scaling exponent in the range of 2 to $3(95 \%$ confidence intervals overlap with this range, Table 2) indi- 


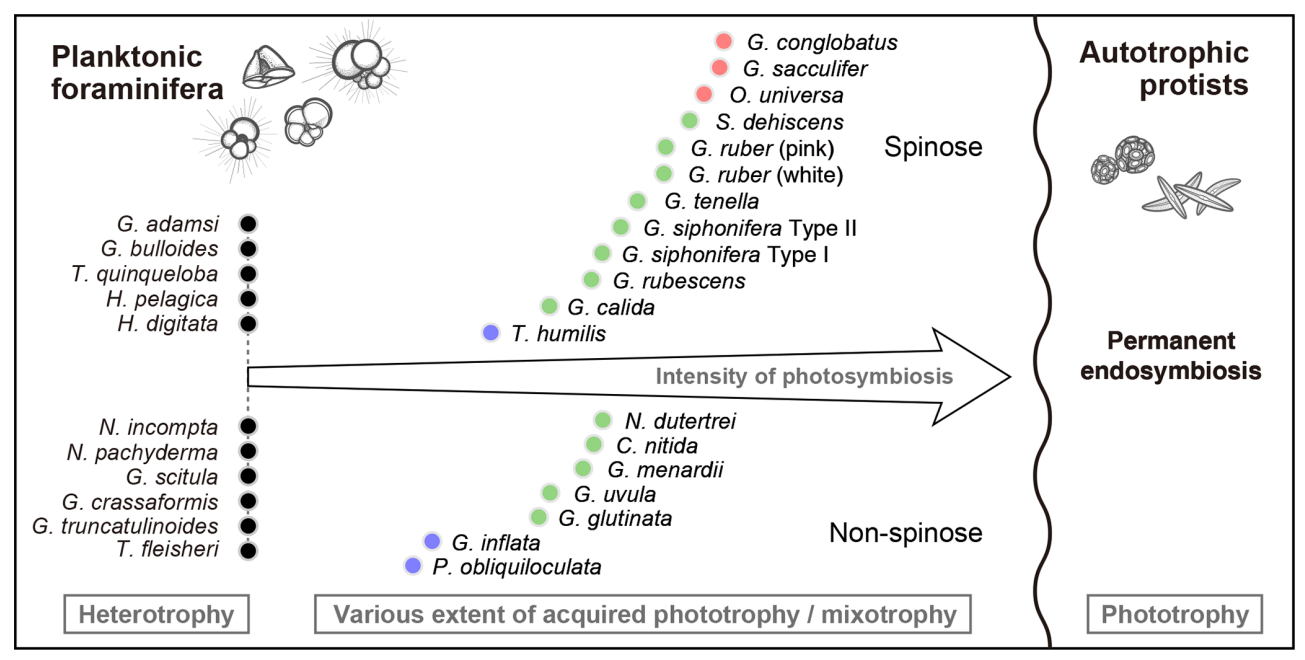

Figure 11. A conceptual diagram of the spectrum of planktonic foraminiferal photosymbiosis along the trophic gradient between permanent endosymbiosis (right) resulting in permanently integrated plastid (not found in planktonic foraminifera) and heterotrophy (left). Foraminiferal species are ordinated on the basis of their PC1 score of the principal component analysis conducted in this study (Fig. 9). The symbol colors correspond to those in Fig. 9. Foraminiferal photosymbiosis has been acquired regardless of their morphological features (i.e., spinose or non-spinose and macroperforate or microperforate). Please note that in planktonic foraminifera, the sexually reproduced new generation must acquire symbionts from the environment.

cates that the Chl $a$ content, indirectly reflecting the symbiont biomass, increased almost proportionally to the host's test volume. This kind of size scaling across different species of planktonic foraminifera suggests a robust relationship between the host and symbionts.

The other notable point in the test size-Chl $a$ relationship is that the spinose species, irrespective of their symbiont type, commonly have more Chl $a$ compared to the non-spinose species (Fig. 10). For example, when the test size is ca. $300 \mu \mathrm{m}$, the macroperforate spinose group has almost 5 times more Chl $a$ than the microperforate nonspinose group, and 10 times more than the macroperforate non-spinose group. The light-dark rhythm of symbiont deployment along the spines was commonly observed in Globigerinoides, Orbulina and Globigerinella species (Anderson and Bé, 1976; Bé et al., 1977; Hemleben and Spindler, 1983; Takagi et al., 2016). Considering this phenomenon, the presence of spines may facilitate symbiosis or at least allows the harboring of a larger symbiont population. For example, efficient illumination for each symbiont cell and maximizing total photosynthetic rates can be achieved due to the spherical distribution of symbionts along the radiating spines. The distribution would also enhance their availability of nutrients or dissolved inorganic carbon for photosynthesis, which should be quickly exhausted when symbionts are sequestered inside the test. These photosynthetic advantages derived from spine possession may contribute to the higher $\mathrm{Chl} a$ content in the spinose species. Such advantages may also be involved with their higher Chl $a$ / biomass (Fig. 7). Moreover, clear clusters correspond to each of the following morphogroups: macroperforate spinose, macroperforate non-spinose, and microper- forate non-spinose (Fig. 10). In addition to the possession of spines, the overall ecology such as depth habitat and the type of prey differs among the groups. Therefore, the light availability as a function of depth and the internal nutrient supply from the host to the symbionts (i.e., prey of the host) can differ among the groups, which would affect the distribution of the plots. If such environmental or microenvironmental conditions surrounding the symbionts are measurable or numerically modeled, our understanding of the differences and the controlling factors of symbiont abundance would be improved.

\subsection{Photophysiology and host-symbiont partnerships}

When species are grouped according to symbiont type, dinoflagellate ( $O$. universa, $G$. sacculifer, $G$. conglobatus, $S$. dehiscens, G. ruber, G, tenella, and G. rubescens) or pelagophyte (G. siphonifera Type II and N. dutertrei) (Table 1), photophysiological parameters are significantly different between these groups. The $\mathrm{Chl} a /$ biomass and $F_{\mathrm{v}} / F_{\mathrm{m}}$ values are higher for dinoflagellate-bearing species $(p \ll 0.01$ and $p=0.012$, respectively; Figs. 7 and $8 \mathrm{a}$ ), and $\sigma_{\mathrm{PSII}}$ values are higher for pelagophyte-bearing species ( $p \ll 0.01$, Fig. 8b). As far as the species whose symbionts are known are compared, it seems that the symbiont photophysiology is overall related to the type of symbiont rather than the host size or the host's morphological group. In fact, we previously published experimental results on photophysiology of cultured G. sacculifer (dinoflagellate bearing) and G. siphonifera Type II (pelagophyte bearing), and reported lower $F_{\mathrm{v}} / F_{\mathrm{m}}$ and higher $\sigma_{\mathrm{PSII}}$ in G. siphonifera Type II than in G. sacculifer (Tak- 
agi et al., 2016). In this study, what we observed is the same tendency of photophysiology corresponding to the type of symbionts regardless of the phylogenetic position the host.

Previous studies revealed high light-adapted photophysiology of dinoflagellate symbionts in $O$. universa and G. sacculifer (Jørgensen et al., 1985; Spero and Parker, 1985; Rink et al., 1998) based on the parameters in photosynthesis-irradiance (P-I) curves. They reported highsaturation irradiance $\left(I_{k}=386 \mu \mathrm{mol}\right.$ photon $\mathrm{m}^{-2} \mathrm{~s}^{-1}$; Spero and Parker, 1985), and no photoinhibition at as high as $4000 \mu \mathrm{mol}$ photon $\mathrm{m}^{-2} \mathrm{~s}^{-1}$ (Jørgensen et al., 1985). By definition, a saturation irradiance $\left(I_{k}\right)$ is inversely proportional to the extrapolated initial slope $(\alpha)$ in a P-I curve. Since the slope $\alpha$ takes into account that the light absorbed by the algal cell is proportional to the functional absorption cross section of PSII ( $\left.\sigma_{\text {PSII }}\right), I_{k}$ should be inversely related to $\sigma_{\text {PSII }}$ (Falkowski and Raven, 2007). Therefore, the high $I_{k}$ reported for dinoflagellate symbionts is consistent with the low $\sigma_{\text {PSII }}$ value observed in our results. Although $I_{k}$ or $\alpha$ of pelagophyte-bearing species has not been reported, the high $\sigma_{\text {PSII }}$ value for pelagophyte-bearing species, vice versa, indicates low-light acclimated photophysiology. This observation is consistent with the living depth of the involved species. In general, dinoflagellate-bearing species such as $G$. ruber and G. sacculifer prefer a more shallow habitat, and pelagophyte-bearing species such as $N$. dutertrei and $G$. siphonifera Type II prefer relatively deeper water (Rebotim et al., 2017). Moreover, when G. siphonifera Type I and Type II are compared, the Type I species, which has haptophyte symbionts, shows a significantly lower $\sigma_{\mathrm{PSII}}$ value than the Type II species (Fig. 8b). The previous report on the difference in pigment content of these types also implied a deeper habitat for G. siphonifera Type II (Bijma et al., 1998). The $\sigma_{\mathrm{PSII}}$ value difference revealed in this study supports their arguments. Furthermore, even in the time before the type difference of this species was recognized, G. siphonifera was often reported to have a bimodal vertical distribution (Tolderlund and Bé, 1971). This possibly reflects the difference of the light preference of their associating symbionts. The current knowledge on $\sigma_{\mathrm{PSII}}$ in foraminifera is still limited, but the observed consistency in their known depth preferences indicates that the symbiont acclimation potential may be one of the factors constraining the habitat selection of the host species.

The dinoflagellate-bearing species, G. ruber (pink) shows high $F_{\mathrm{v}} / F_{\mathrm{m}}$ values with relatively small variation, and, interestingly, it is significantly higher than that of G. ruber (white) (Fig. 8a). In general, $F_{\mathrm{v}} / F_{\mathrm{m}}$ values vary depending the nutrient availability (Kolber et al., 1988; Parkhill et al., 2001); i.e., the higher $F_{\mathrm{v}} / F_{\mathrm{m}}$ values may be achieved by the higher nutrient supply to the symbionts. A recent study showed that the inorganic nutrients in ambient seawater do not affect the $F_{\mathrm{v}} / F_{\mathrm{m}}$ values of $G$. sacculifer, suggesting that it is the internal supply of nutrients from the host to symbionts that can influence the $F_{\mathrm{v}} / F_{\mathrm{m}}$ values (Takagi et al., 2018). In this con- text, it can be assumed that among the species having the same symbionts, the higher $F_{\mathrm{v}} / F_{\mathrm{m}}$ value possibly reflects the higher level of host-symbiont interaction. If this is the case among the species used for the statistical analysis, it can be said that the strongest symbiotic relationship has been established in G. ruber (pink). In fact, the interspecific comparison may not be suitable because the other environmental factors which might affect the physiology of the hostsymbiont consortia, such as seawater temperature, salinity, light intensity, and prey abundance, are not considered in this study. Globigerinoides ruber (pink) was collected only from the Atlantic cruise, whereas G. ruber (white) was collected from various oceanic realms (Table S1). The difference in the range of sampling region may also be involved with relatively constrained $F_{\mathrm{v}} / F_{\mathrm{m}}$ values in $G$. ruber (pink) and contrastingly large variability in G. ruber (white). In order to discuss in more detail the interspecific photophysiological differences, comparison of the photophysiological parameters for specimens cultured under controlled conditions or the compilation of individual data collected from a similar environmental condition is needed. Besides, since various potential factors are affecting the photophysiology (e.g., host taxonomy, symbiont taxonomy, light, nutrient, etc.), statistical modeling approaches such as generalized linear or additive mixed models would be useful to elucidate which factor is important to determine the photophysiology.

\section{Conclusion and future perspectives}

The present study extends our understanding of photosymbiosis in modern planktonic foraminifera. A thorough investigation of 30 foraminiferal species was performed using FRR fluorometry. Eleven species show no signal of photosynthesis and are confirmed to be non-symbiotic. Nineteen species show the functionality of photosynthesis, which is convincing evidence of photosymbiosis. Of these species, we found significant positive correlations in test size-Chl $a$ content relationship in 16 species, which are regarded to show persistent symbiotic relationships. Especially, dinoflagellatebearing $G$. sacculifer, G. conglobatus, and O. universa have higher Chl $a$ densities, probably reflecting a higher potential for photosynthesis. The remaining three species, T. humilis, $P$. obliquiloculata, and $G$. inflata, show no significant size scaling relationship in Chl $a$ content. Moreover, their $F_{\mathrm{v}} / F_{\mathrm{m}}$ values and the symbiont possession rates are comparatively low. Based on a PCA using the four features relating to photosymbiosis, we rank 30 species using an integrated scale (the PC1 score scale). Finally, we propose a new framework of photosymbiosis in planktonic foraminifera as a continuous spectrum of photosymbiosis. In the context of nutrition, this concept represents a varying degree of mixotrophy which is commonly seen in marine planktonic organisms (Stoecker et al., 2017). Interestingly, photophysiology may be basically determined by the type of the symbiont, regardless of the 
phylogenetic position of the host and its test morphology. Physiological parameters, in particular $\sigma_{\text {PSII }}$, seem to correspond to the overall depth habitat of the host foraminifera. It might imply that the habitat of the host foraminifera is partly governed by the symbiont type. However, what is missing in our study is the taxonomy of the symbionts. Combining the information of FRR fluorometry, DNA, and microscopic evidence on their ultrastructure will provide a more comprehensive understanding of photosymbiosis in planktonic foraminifera.

Data availability. All data obtained in this study are in Supplement.

Supplement. The supplement related to this article is available online at: https://doi.org/10.5194/bg-16-3377-2019-supplement.

Author contributions. HT conceived the project. KK, TF, and KM advised on methodology. HT, KK, HS, CS, and MK participated in sampling and collected planktonic foraminifera. HT carried out the onboard lab work with help of KK, TF, CS, and MK. TF and CS contributed to photophysiological measurement and data analysis. HT carried out data analysis and statistical analysis. HT wrote the paper, and KK, TF, HS, CS, MK, and KM provided critical discussions and suggestions to the paper.

Competing interests. The authors declare that they have no conflict of interest.

Acknowledgements. We acknowledge the captains and the shipboard members of RV Mirai, RV Kaiyo, RV Shinsei Maru, RV Hakuho Maru, and RV Meteor. We would like to thank the staff at the Misaki Marine Biological Station (The University of Tokyo), the staff at the Sesoko Station, the Tropical Biosphere Research Center (University of the Ryukyus), and Tomohiko Kikuchi and Shinji Shimode (Yokohama National University) for helping with the sampling. We would like to thank Howard J. Spero and Ralf Schiebel for their constructive review and Martina Prazeres for her valuable discussion; the paper was greatly improved by their suggestions. The graphs were drawn with Generic Mapping Tools (Wessel and Smith, 1998).

Financial support. This research has been supported by the Japan Society for the Promotion of Science (grant nos. 24121003 (Hiroaki Saito), 25740014 and 16K00532 (Tetsuichi Fujiki), 13J05477, 16H06738, 17J05887, and 18K14507 (Haruka Takagi)).

Review statement. This paper was edited by Hiroshi Kitazato and reviewed by H. J. Spero and Ralf Schiebel.

\section{References}

Anderson, O. R. and Bé, A. W. H.: The ultrastructure of a planktonic foraminifer, Globigerinoides sacculifer (Brady), and its symbiotic dinoflagellates, J. Foramin. Res., 6, 1-21, 1976.

Anderson, O. R., Spindler, M., Bé, A. W. H., and Hemleben, C.: Trophic activity of planktonic foraminifera, Journal of Marine Biological Association of the UK, 59, 791-799, 1979.

Bé, A. W. H., Hemleben, C., Anderson, O. R., Spindler, M., Hacunda, J., and Tuntivate-Choy, S.: Laboratory and field observations of living planktonic foraminifera, Micropaleontology, 23, 155-179, 1977.

Bé, A. W. H., Anderson, O. R., Faber, W. W. Jr., and Caron, D. A.: Sequence of morphological and cytoplasmic changes during gametogenesis in the planktonic foraminifer Globigerinoides sacculifer (Brady), Micropaleontology, 29, 310-325, 1983.

Bernhard, J. M. and Bowser, S. S.: Benthic foraminifera of dysoxic sediments: chloroplast sequestration and functional morphology, Earth-Sci. Rev., 46, 149-165, 1999.

Bijma, J., Hemleben, C., Huber, B. T., Erlenkeuser, H., and Kroon, D.: Experimental determination of the ontogenetic stable isotope variability in two morphotypes of Globigerinella siphonifera (d'Orbigny), Mar. Micropaleontol., 35, 141-160, 1998.

Bird, C., Darling, K. F., Russell, A. D., Davis, C. V., Fehrenbacher, J., Free, A., Wyman, M., and Ngwenya, B. T.: Cyanobacterial endobionts within a major marine planktonic calcifier (Globigerina bulloides, Foraminifera) revealed by $16 \mathrm{~S}$ rRNA metabarcoding, Biogeosciences, 14, 901-920, https://doi.org/10.5194/bg14-901-2017, 2017.

Bird, C., Darling, K. F., Russell, A. D., Fehrenbacher, J., Davis, C. V., Free, A., and Ngwenya, B. T.: 16S rRNA gene metabarcoding and TEM reveals different ecological strategies within the genus Neogloboquadrina (planktonic foraminifer), Plos ONE, 13, e0191653, https://doi.org/10.1371/journal.pone.0191653, 2018.

Bolli, H. M., Saunders, J. B., and Perch-Nielsen, K.: Plankton Stratigraphy, Vol. 1, Cambridge University Press, Cambridge, 599 pp., 1985.

Boudagher-Fadel, M. K., Banner, F. T., and Whittaker, J. E.: The Early Evolutionary History of the Planktonic Foraminifera, Springer, the Netherlands, 269 pp., 1997.

Caron, D. A.: Symbiosis and mixotrophy among pelagic microorganisms, in: Microbial Ecology of the Oceans, edited by: Kirchman, D. L., Wiley-Liss, Inc., New York, 495-523, 2000.

Ezard, T. H. G., Aze, T., Pearson, P. N., and Purvis, A.: Interplay between changing climate and species' ecology drives macroevolutionary dynamics, Science, 332, 349-351, 2011.

Ezard, T., Edgar, K. M., and Hull, P. M.: Environmental and biological controls on size-specific $\delta^{13} \mathrm{C}$ and $\delta^{18} \mathrm{O}$ in recent planktonic foraminifera, Paleoceanography, 30, 151-173, 2015.

Faber, W. W. Jr., Anderson, O. R., Lindsey, J. L., and Caron, D. A.: Algal-foraminiferal symbiosis in the planktonic foraminifer Globigerinella aequilateralis, I. Occurrence and stability of two mutually exclusive chrysophyte endosymbionts and their ultrastructure, J. Foramin. Res., 18, 334-343, 1988.

Faber, W. W. Jr., Anderson, O. R., and Caron, D. A.: Algalforaminiferal symbiosis in the planktonic foraminifer Globigerinella aequilateralis., II. Effects of two symbiont species on foraminiferal growth and longevity, J. Foramin. Res., 19, 185193, 1989. 
Falkowski, P. G. and Raven, J. A.: Aquatic photosynthesis, 2nd Edn., Princeton University Press, Princeton, 484 pp., 2007.

Fehrenbacher, J. S., Russell, A. D., Davis, C. V., Spero, H. J., Chu, E., and Hönisch, B.: Ba/Ca ratios in the non-spinose planktic foraminifer Neogloboquadrina dutertrei: Evidence for an organic aggregate microhabitat, Geochim. Cosmochim. Ac., 236, 361-372, 2018.

Fenton, I. S., Pearson P. N., Dunkley Jones T., and Purvis, A.: Environmental predictors of diversity in recent planktonic foraminifera as recorded in marine sediments, PLoS ONE, 11, e0165522, https://doi.org/10.1371/journal.pone.0165522, 2016.

Fujiki, T., Takagi, H., Kimoto, K., Kurasawa, A., Yuasa T., and Mino, Y.: Assessment of algal photosynthesis in planktic foraminifers by fast repetition rate fluorometry, J. Plankton Res., 36, 1403-1407, 2014.

Gast, R. J. and Caron, D. A.: Molecular phylogeny of symbiotic dinoflagellates from Foraminifera and Radiolaria, Mol. Biol. Evol., 13, 1192-1197, 1996.

Gast, R. J., McDonnell, T. A., and Caron, D. A.: srDNA-based taxonomic affinities of algal symbionts from a planktonic foraminifera and a solitary radiolarian, J. Phycol., 36, 172-177, 2000.

Gastrich, M. D.: Ultrastructure of a new intracellular symbiotic alga found within planktonic foraminifera, J. Phycol., 23, 623-632, 1987.

Gastrich, M. D. and Bartha, R.: Primary productivity in the planktonic foraminifer Globigerinoides ruber (d'Orbigny), J.f Foramin. Res., 18, 137-142, 1988.

Hallock, P.: Algal symbiosis: a mathematical analysis, Mar. Biol., 62, 249-255, 1981.

Hemleben, C. and Spindler, M.: Recent advances in research on living planktonic foraminifera, Utrecht Micropaleontological Bulletins, 30, 141-170, 1983.

Hemleben, C., Spindler, M., and Anderson, O. R.: Modern planktonic foraminifera, Springer-Verlag, New York, 363 pp., 1989.

Henehan, M. J., Rae, J. W. B., Foster, G. L., Erez, J., Prentice, K. C., Kucera, M., Bostock, H. C., Martínez-Botí, M. A., Milton, J. A., Wilson, P. A., Marshall, B. J., and Elliott, T.: Calibration of the boron isotope proxy in the planktonic foraminifera Globigerinoides ruber for use in palaeo- $\mathrm{CO}_{2}$ reconstruction, Earth Planet. Sc. Lett., 364, 111-122, 2013.

Hönisch, B., Bijma, J., Russell, A. D., Spero, H. J., Palmer, M. R., Zeebe, R. E., and Eisenhauer, A.: The influence of symbiont photosynthesis on the boron isotopic composition of foraminifera shells, Mar. Micropaleontol., 49, 87-96, 2003.

Huber, B. T., Bijma, J., and Darling, K.: Cryptic speciation in the living planktonic foraminifer Globigerinella siphonifera (d'Orbigny), Paleobiology, 23, 33-62, 1997.

Hull, P. M.: Emergence of modern marine ecosystems, Curr. Biol., 27, R466-R469, 2017.

Jørgensen, B. B., Erez, J., Revsbech, N. P., and Cohen, Y.: Symbiotic photosynthesis in a planktonic foraminiferan Globigerinoides sacculifer (Brady), studied with microelectrodes, Limnol. Oceanogr., 30, 1253-1267, 1985.

Kolber, Z. S. and Falkowski, P. G.: Use of active fluorescence to estimate phytoplankton photosynthesis in situ, Limnol. Oceanogr., 38, 1646-1665, 1993.
Kolber, Z. S., Zehr, J., and Falkowski, P. G.: Effects of growth irradiance and nitrogen limitation on photosynthetic energy conversion in Photosystem II, Plant Physiol., 88, 923-929, 1988.

Kolber, Z. S., Prášil, O., and Falkowski, P. G.: Measurements of variable chlorophyll fluorescence using fast repetition rate techniques: defining methodology and experimental protocols, Biochim. Biophys. Acta, 1367, 88-106, 1998.

Lee, J. J.: Algal symbiosis in larger foraminifera, Symbiosis, 42, 63-75, 2006.

Lee, J. J., Freudenthal, H. D., Kossoy, V., and Bé, A. W. H.: Cytological observations on two planktonic foraminifera, Globigerina bulloides and Globigerinoides ruber, J. Protozool., 12, 531-542, 1965.

LeKieffre, C., Spero, H. J., Russell, A. D., Fehrenbacher, J. S., Geslin, E., and Meibom, A.: Assimilation, translocation, and utilization of carbon between photosynthetic symbiotic dinoflagellates and their planktic foraminifera host, Mar. Biol., 165, 15 pp., https://doi.org/10.1007/s00227-018-3362-7, 2018.

Locarnini, R. A., Mishonov, A. V., Antonov, J. I., Boyer, T. P., Garcia, H. E., Baranova, O. K., Zweng, M. M., Paver, C. R., Reagan, J. R., Johnson, D. R., Hamilton, M., and Seidov, D.: World Ocean Atlas 2013, Vol. 1, Temperature, in: NOAA Atlas NESDIS 73, edited by: Levitus, S. and Mishonov, A., 40 pp., 2013.

Lombard, F., Erez, J., Michel, E., and Labeyrie, L.: Temperature effect on respiration and photosynthesis of the symbiont-bearing planktonic foraminifera Globigerinoides ruber, Orbulina universa, and Globigerinella siphonifera, Limnol. Oceanogr., 54, 210-218, 2009.

Movellan, A.: La biomasse des foraminifères planctoniques actuels et son impact sur la pompe biologique de carbone, $\mathrm{PhD}$ Thesis, University of Angers, 129 pp., 2013.

Norris, R. D.: Biased extinction and evolutionary trends, Paleobiology, 17, 388-399, 1991.

Norris, R. D.: Symbiosis as an evolutionary innovation in the radiation of Paleocene planktonic foraminifera, Paleobiology, 22, 461-480, 1996.

Parkhill, J.-P., Maillet, G., and Cullen, J. J.: Fluorescence-based maximal quantum yield for PSII as a diagnostic of nutrient stress, J. Phycol., 37, 517-529, 2001.

Pearson, P. N., Shackleton, N. J., and Hall, M. A.: Stable isotope paleoecology of middle Eocene planktonic foraminifera and multispecies isotope stratigraphy, DSDP Site 523, South Atlantic, J. Foramin. Res., 23, 123-140, 1993.

Pillet, L., de Vargas, C., and Pawlowski, J.: Molecular identification of sequestered diatom chloroplasts and kleptoplastidy in foraminifera, Protist, 162, 394-404, 2011.

R Core Team: R: a language and environment for statistical computing, R Foundation for Statistical Computing, Vienna, Austria, https://www.R-project.org/, last access: 1 December 2016.

Rebotim, A., Voelker, A. H. L., Jonkers, L., Waniek, J. J., Meggers, H., Schiebel, R., Fraile, I., Schulz, M., and Kucera, M.: Factors controlling the depth habitat of planktonic foraminifera in the subtropical eastern North Atlantic, Biogeosciences, 14, 827-859, https://doi.org/10.5194/bg-14-827-2017, 2017.

Rink, S., Kühl, M., Bijma, J., and Spero, H. J.: Microsensor studies of photosynthesis and respiration in the symbiotic foraminifer Orbulina universa, Mar. Biol., 131, 583-595, 1998.

Schiebel, R. and Hemleben, C.: Planktic Foraminifers in the Modern Ocean, Springer-Verlag, Berlin Heidelberg, 358 pp., 2017. 
Schmidt, C., Heinz, P., Kucera, M., and Uthicke, S.: Temperatureinduced stress leads to bleaching in larger benthic foraminifera hosting endosymbiotic diatoms, Limnol. Oceanogr., 56, 15871602, 2011.

Seears, H. A., Darling, K. F., and Wade, C. M.: Ecological partitioning and diversity in tropical planktonic foraminifera, BMC Evol. Biol., 12, 54, https://doi.org/10.1186/1471-2148-12-54, 2012.

Shaked, Y. and de Vargas, C.: Pelagic photosymbiosis: rDNA assessment of diversity and evolution of dinoflagellate symbionts and planktonic foraminiferal hosts, Mar. Ecol. Prog. Ser., 325, 59-71, 2006.

Spero, H. J. and DeNiro, M. J.: The influence of symbiont photosynthesis on the $\delta^{18} \mathrm{O}$ and $\delta^{13} \mathrm{C}$ values of planktonic foraminiferal shell calcite, Symbiosis, 4, 213-228, 1987.

Spero, H. J. and Parker, S. L.: Photosynthesis in the symbiotic planktonic foraminifer Orbulina universa, and its potential contribution to oceanic primary productivity, J. Foramin. Res., 15, 273-281, 1985.

Spindler M. and Hemleben, C.: Symbionts in planktonic Foraminifera (Protozoa), in: Endocytobiology, endosymbiosis and cell biology, edited by: Schwemmler, W. and Schenk, H. E. A., Walter de Gruyter \& Co, Berlin, 133-140, 1980.

Spindler M., Hemleben, C., Salomons, J. B., and Smit, L. P.: Feeding behavior of some planktonic foraminifers in laboratory cultures, J. Foramin. Res., 14, 237-249, 1984.

Stoecker, D. K.: Conceptual models of mixotrophy in planktonic protists and some ecological and evolutionary implications, Eur. J. Protistol., 34, 281-290, 1998.

Stoecker, D. K., Johnson, M. D., de Vargas, C., and Not, F.: Acquired phototrophy in aquatic protists, Aquat. Microb. Ecol., 57, 279-310, 2009.
Stoecker, D. K., Hansen, P. J., Caron, D. A., and Mitra, A.: Mixotrophy in the marine plankton, Annu. Rev. Mar. Sci., 9, 311-335, 2017.

Takagi, H., Kimoto, K., Fujiki, T., Kurasawa, A., Moriya, K., and Hirano, H.: Ontogenetic dynamics of photosymbiosis in cultured planktic foraminifers revealed by fast repetition rate fluorometry, Mar. Micropaleontol., 122, 44-52, 2016.

Takagi, H., Kimoto, K., Fujiki, T., and Moriya, K.: Effect of nutritional condition on photosymbiotic consortium of cultured Globigerinoides sacculifer (Rhizaria, Foraminifera), Symbiosis, 76, 25-39, 2018.

Tolderlund, D. S. and Bé, A. W. H.: Seasonal distribution of planktonic Foraminifera in the western North Atlantic, Micropaleontology, 17, 297-329, 1971.

Uthicke, S.: Photosynthetic efficiency and rapid light curves of sediment-biofilms along a water quality gradient in the Great Barrier Reef, Australia, Mar. Ecol. Prog. Ser., 322, 61-73, 2006.

Weiner, A., Aurahs, R., Kurasawa, A., Kitazato, H., and Kucera, M.: Vertical niche partitioning between cryptic sibling species of a cosmopolitan marine planktonic protist, Mol. Ecol., 21, 40634073, 2012.

Wessel, P. and Smith, W. H. F.: New, improved version of generic mapping tools released, Earth \& Space Sciences News, Transactions of the American Geophysical Union, 79, 579 pp., https://doi.org/10.1029/98EO00426, 1998.

Yasuhara, M., Tittensor, D. P., Hillebrand, H., and Worm, B.: Combining marine macroecology and palaeoecology in understanding biodiversity: microfossils as a model, Biol. Rev., 92, 199215, 2017.

Ziegler, M. and Uthicke, S.: Photosynthetic plasticity of endosymbionts in larger benthic coral reef foraminifera, J. Exp. Mar. Biol. Ecol., 407, 70-80, 2011. 